\title{
اثر تقلبات أسعار النفط الخام في الطلب على مصادر الطاقة البديلة للمدة (1973-2008)
}

\author{
خليل غازي حسن و خبات الإن عبدالكريم سعيد
}

قسم الاقتصاد، جامعة دهو ك،كلية الادارة و الاقتصاد، جامعة دهوك، اقليم كوردستان_العر اق

\section{(تاريخ استلام البحث: 1 نيسان، 2019، تاريخ القبول بالنشر: 11 اليول، 2109)}

فيما يشتد الجدل فيما اذا كانت تقلبـات الاسـعار

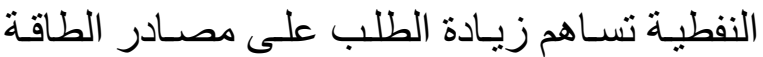

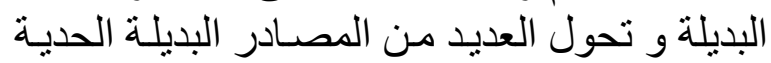

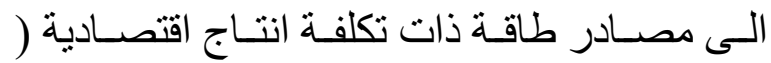

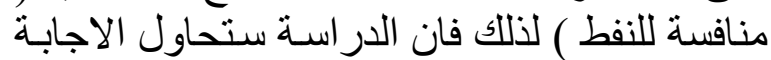
على التسـاؤل: فيمـا اذا كانت التقان التبات في استعار

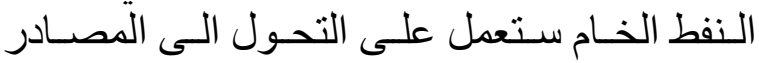

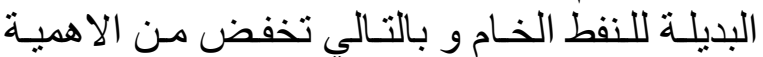

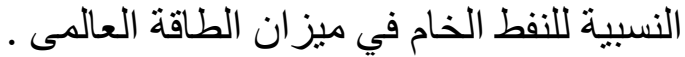
هدف البحث: بهدف البحث إلى فيز تقدير و تحليل الطيل

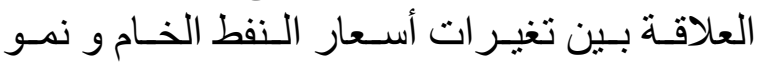

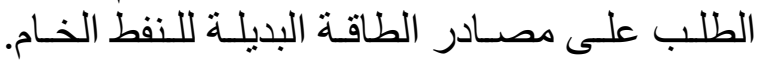

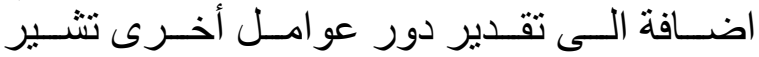

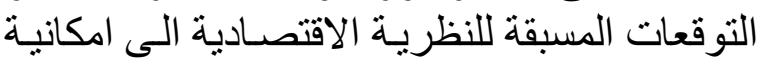
ان تساهم في تحديد الطلب المشار اليه.

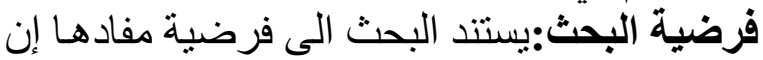

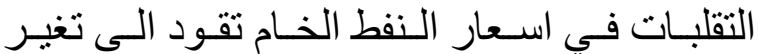
الاهمية النسبية للنفط لصالح مصادر الطاقة البديلة

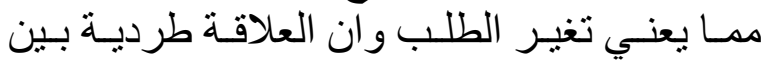

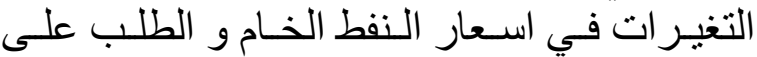
مصنادر الطاقة البديلة . حدود البحث: يقتصر البحث على البدلى المدة (19732008) ، و يتم تقدير نمـاذج للطلب الطاقـة البديلـة

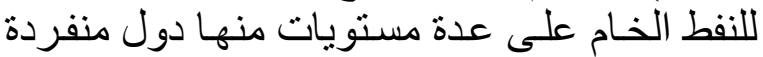

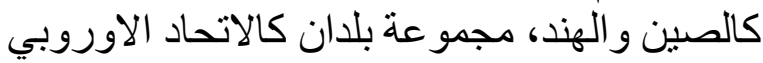

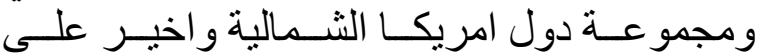
المستوى الاجمالي للعالم. بيانـات البحث : سيعتمد البحث في التحليل على الإلى

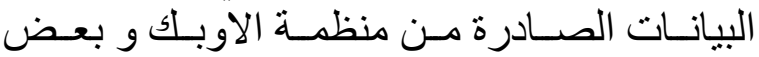

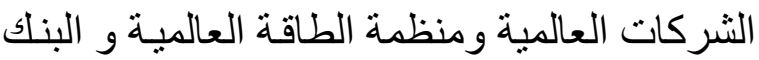

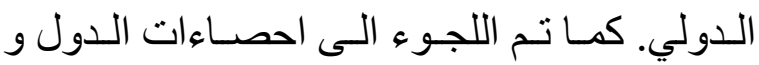

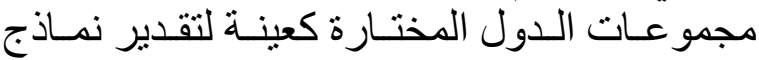
خاصة بها لاغر اض الدور المقارنة.

\section{مقدمة}

يعـد الـفط الخـام احد أهـ المـوارد الناضـبة

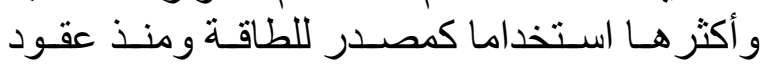
طويلة ولا يز ال يحتل مركز الصدارة في ترثيب

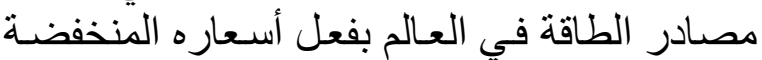

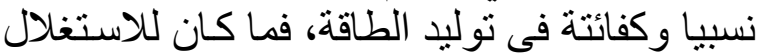

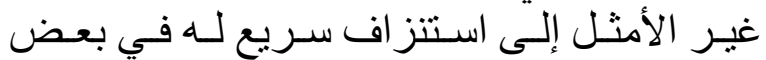
البلدان الصناعية، مثل حالات جفاف الآبار النفطية

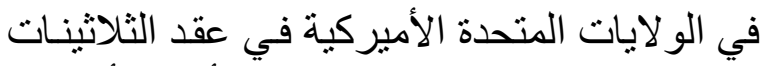

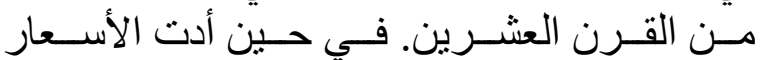

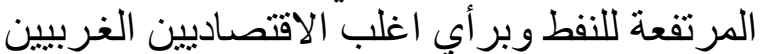

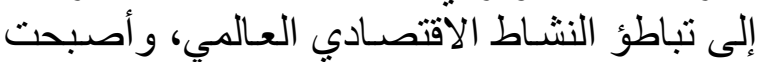

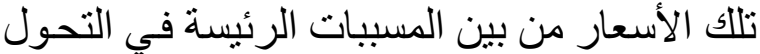
نحو مصادر الطاقة البديلة.

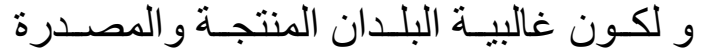

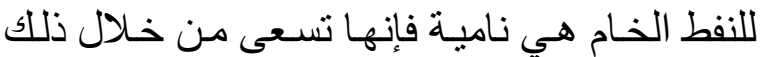

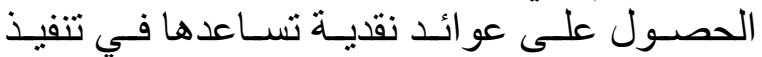
بر امج التنمية الاقتصادية التي تهدف منها تها تطوير

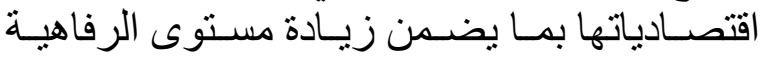

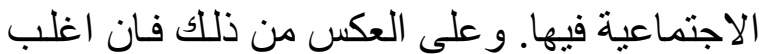

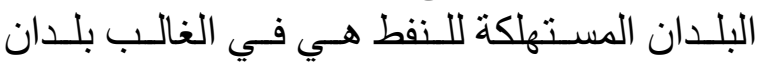
صناعية متقدمة، أب إن النسبة الأكبر من الإنتاج

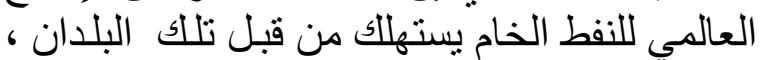

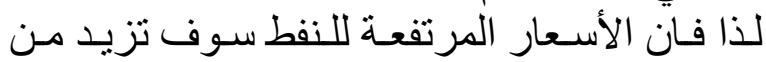

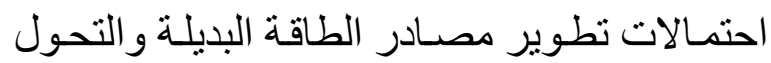

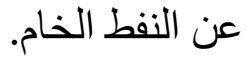

\section{أهمية البحث}

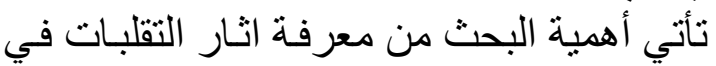

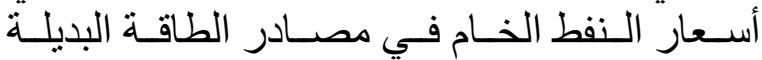
وتطوير ها وبالتالي معرفة اتجاهات الطلب عليه. مشكلة البحث ونئ 
transformation أسعار التحويل)، (Cost

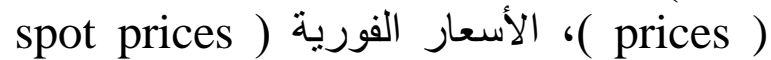
)، (الأسعار الرسمية ( Official prices) و السعر الأعراز الترجيعي (Net Back Arrangement Price) (اسماعيل،بدون تاريخ،46). و قد مر تسعير النفط الخام بمرحلتين هما مرحلة نظام نقطة الأساس

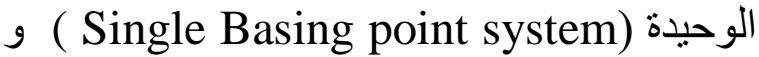
نظام نقطتي الأساس المزدوجة ( Dual Basing ،(Melamid,1962,291-2)(Point system وكان التسعير محور صراع دائم بين البلدان المصدرة والبلدان المستوردة والثركات دات النفئية العالمية التي كانت مسيطرة ولمدة طويلة على النى عملية التسعير. فيما احتلت مسالة تقلبات اسعار النفط حيزا كبيرا في الادبيات و الدراسات التجريبة خلاتل التلال

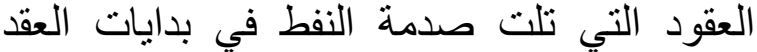
السابع من القرن الماضي التي ساهمت التي التئ التوجه

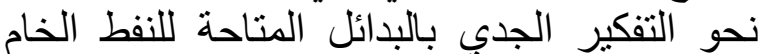
كمصدر للطاقة. فانه سيتم عرض البتل البعض منها لانها

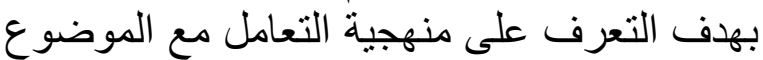

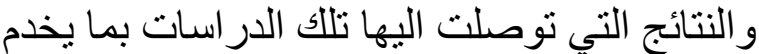

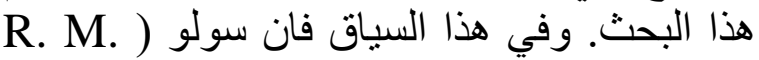

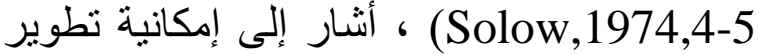

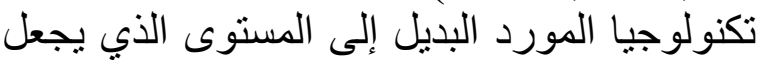

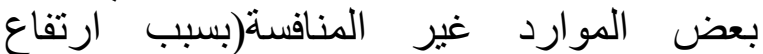
التكاليف أو انخفاض الكفاءة الفنية) مثال ذللك تسيل

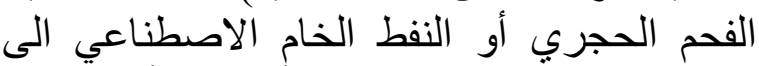

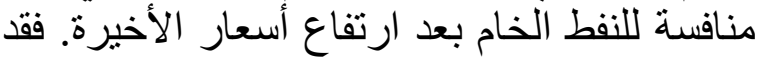
توصلت هذه الدراسة إلى أن الارتفاع في أسعار النفط الخام قد تؤدي بالبلدان المستهلكة إلى البحث البحث

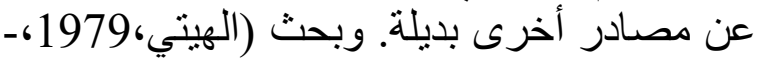
265-264) في آفاق تطوير الدصادر البديلة للنفط الخام و تحديد قدرتها التنافسية مقارنة بالنفط الخام

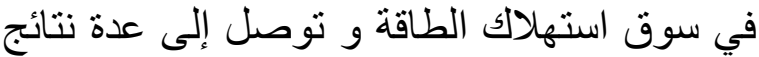
من أهمها إن النفط الخام لا يز ال المصدي المدر الرئيس

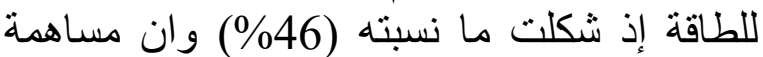
الغاز الطبيعي ازدادت في موازين استهاتلاك الطاقة

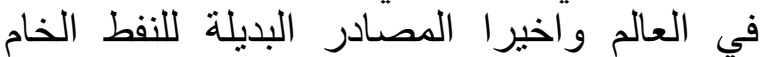
بتتوعها لا تزال متخلفة من حيث مساهمتها في الئي ميز ان استهلاك الطاقة العالمي.
منهجية البحث: لتحقيق أهداف البحث و فرضياته سيتم اعتماد التحليل الاقتصادي للمعلمات التهات التي يتم

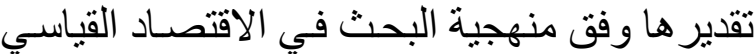

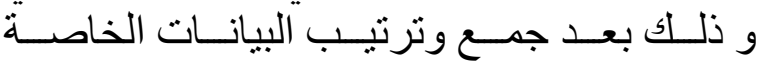
بالمتغير ات الداخلة في النموذج الذي سيتم توني توصيفه

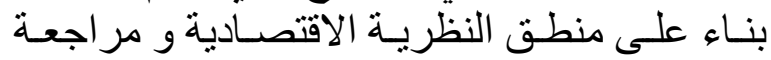

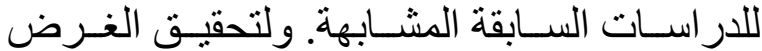

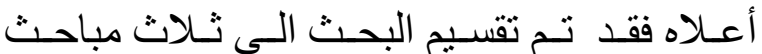

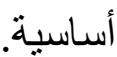
المبحث الأول :ملخل مفاهيمي وعرض مرجعي الإني

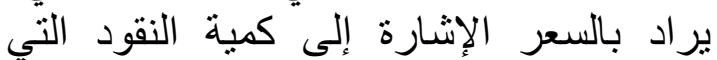
تستخدم للتعبير عن القيمة التي تحددها عمليات التئي

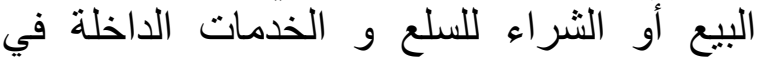

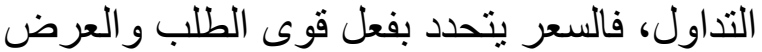

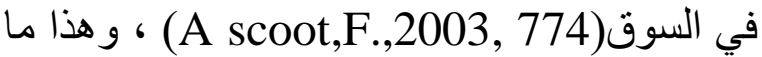
يشير إلى وجود علاقة بين قيمة السلعة أو الخدمة

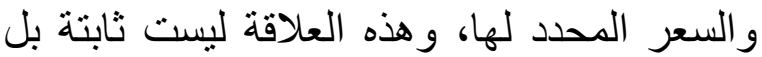

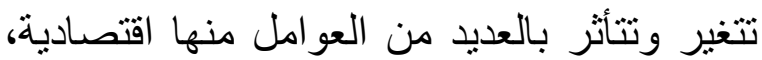
اجتماعية وعو امل سياسية، وعليه ولئ فان سعر النفط أيضا يمثل قيمة النفط بوحدة قياس معينة معبرا عنها بوحدة نقدية محددة في زمانة زمان ومكان ومكان معلومين. أما العلاقة بين سعر النفط و قئة قيمته

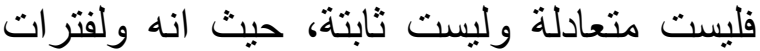
زمنية ماضية كان السعر اقل من قيمة النفط مقاسة

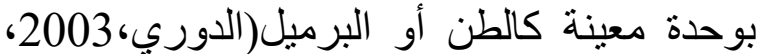

و غالبا ما يعبر عن سعر النفط بالوحدة النقدية

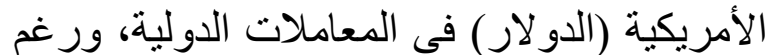

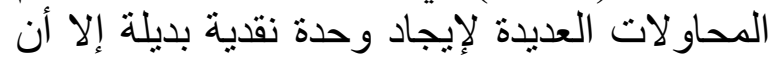
سعر برميل نفطي ارتبط بالدولار الأمريكي كونه لا يز ال أكثر العملات النقدية الدولية قبو لألا أستنادا

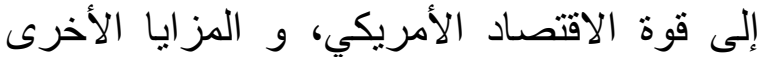

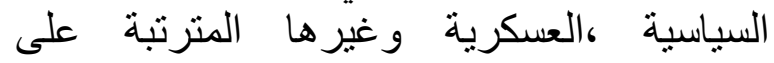
و قد شهي تاريخ تطور الصناعة النفطية أنواعا

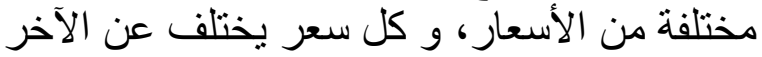
من حيث التعبير عن قيمة السلعة منها:( الأسعار الأر المعلنة ( The posted prices)، الأسعار المتحققة (The Realized price)، أسعار الإثارة (The Reference Prices)، أسعار The Tax-Paid Prices (الكلفة الضريبية 
الخـام كانـت مسـتقرة خـلال الفترة الأولى ولكنهـا

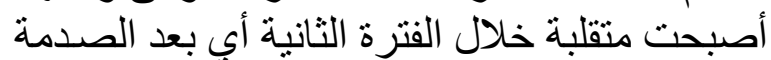

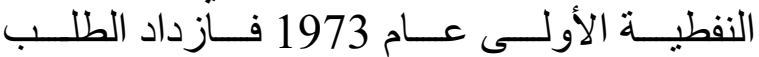

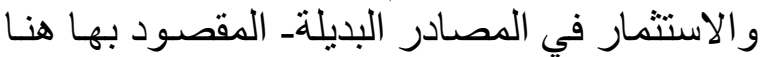

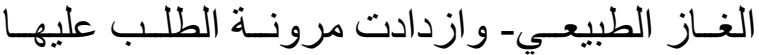

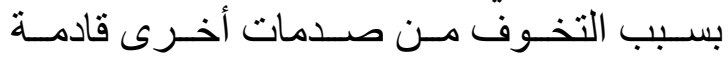

.(Noureddine K.,2002,574-5)

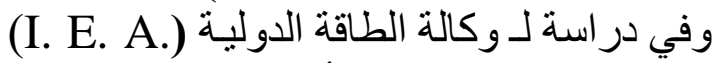
، تم استعر اض التقلبـات في أسعار النفط منذ عام التهام

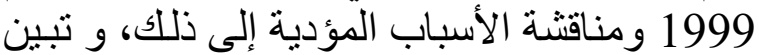

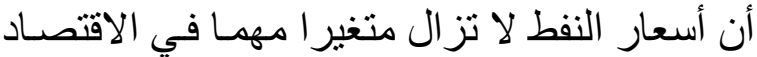

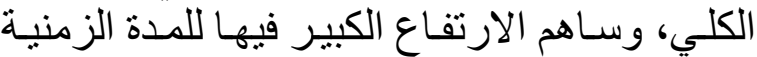

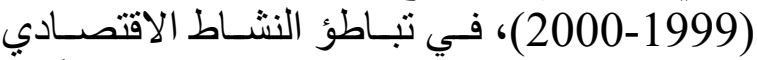

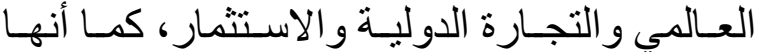

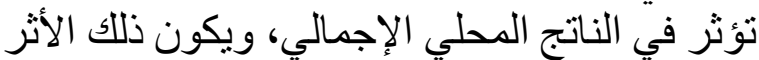
في البلدان الناميـة المستوردة للنفط اكبر منـه في الإني

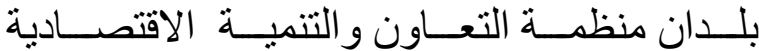

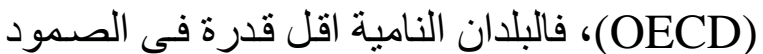

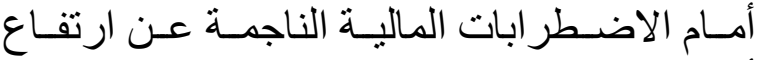
أسعار النفط وتكاليف استير اده(-E.A.A.2004,2

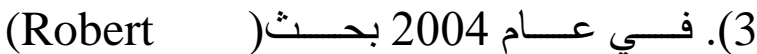

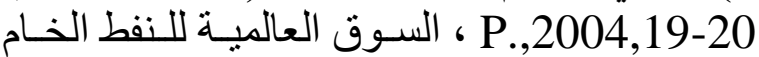
و تبين انه حدثت تقلبات كبيرة في أسعار النفط بين

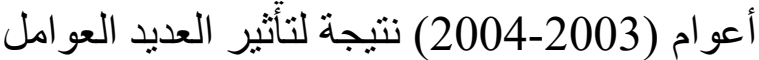
و ان نمو الطلب العالمي على النفط يسبب ضغوطا لتاني

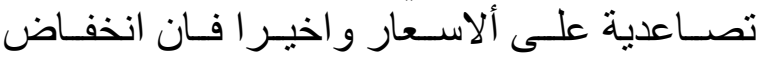

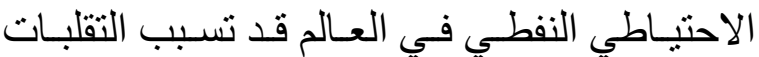

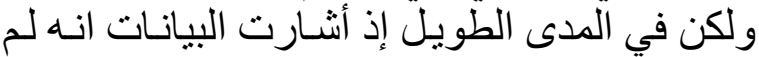

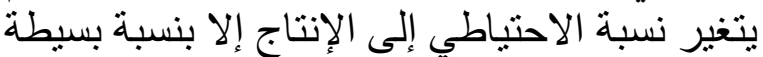

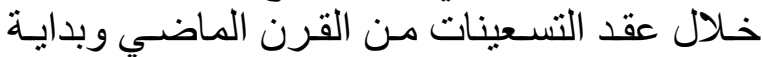

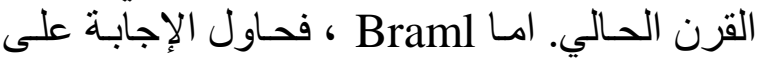

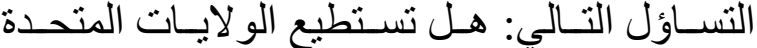

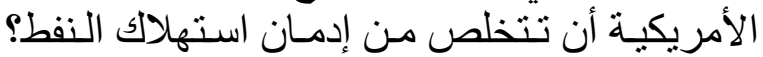

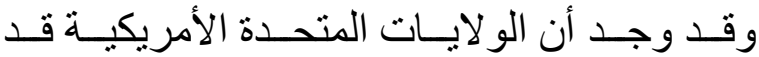

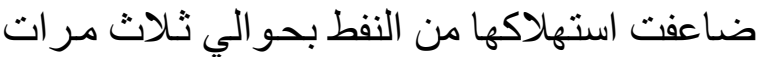

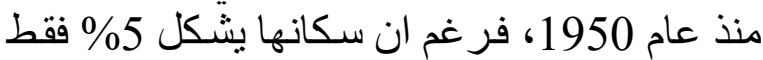
مـن سـكان العـالم الا انهـا تسـتهلك (22.5\%

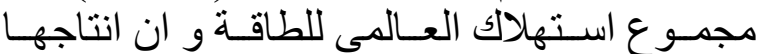

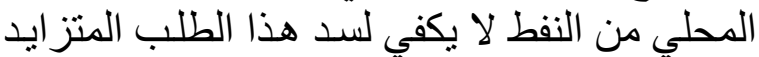

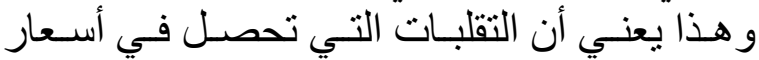

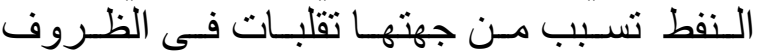

اما سينجر فقام بدر اسة دور السياسات الثلاث ( السياسات الضريبية التي توثر على كلى دن من المنتجين والمستهلكين، و القيود الكمركية، واستعمال الاحتياطي النفطي الاستراتيجي التي التيني

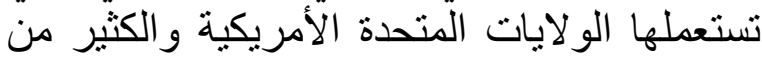

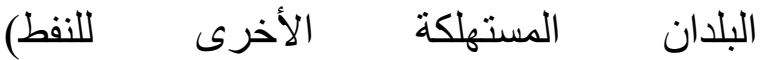
(S.Fred,1987,445-7) النفط،وتوصل الباحث إلى نتيجة مفادها انه بمكن

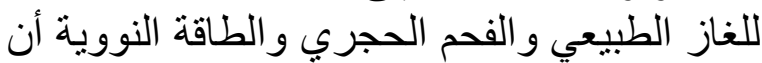
يحلو ا محل النفط في تطبيقات عدة باستثناء قطاع

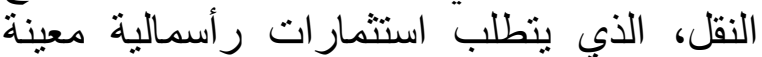
تؤ هله لذلك مستقبلاً، فبالنسبة للسيار ات و الثناحنات

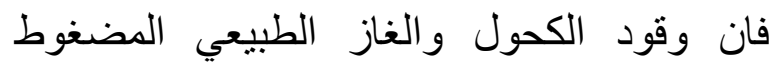
وطاقة البطارية الكهربائية قد تصبح مهمة لوقف الفي ارتفاع أسعار النفط المستقبلية.

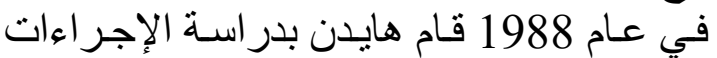

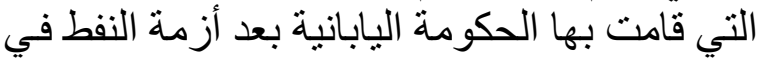

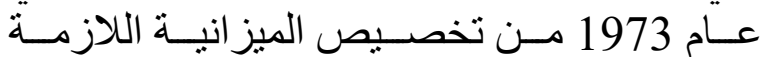

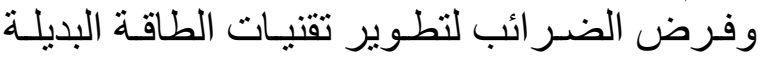

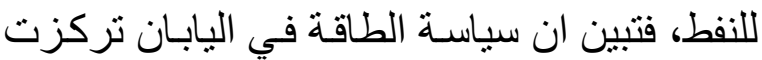
في التحول نحو المصادر البديلة للطاقة مثل الطاقة

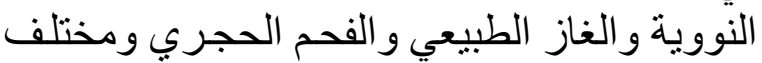

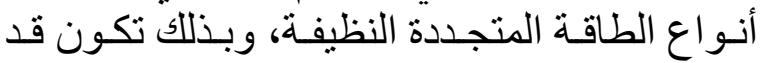

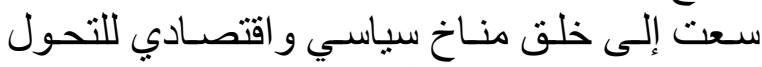

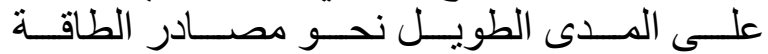

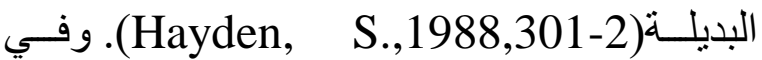

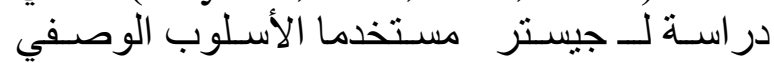
للبيانات و المعلومات للفترة التالية للصدمة النفطية

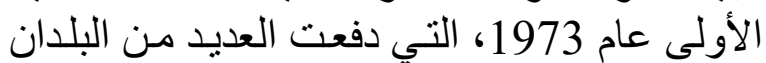

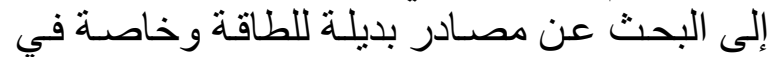

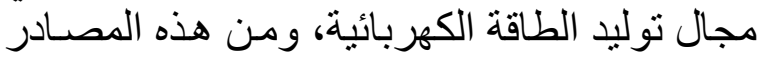

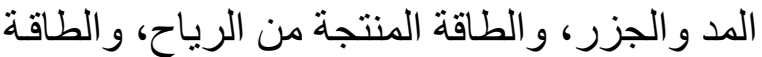

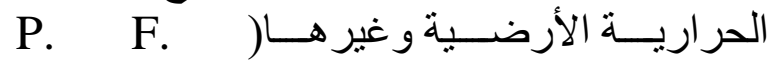

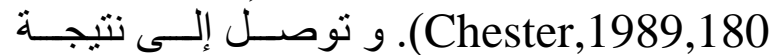

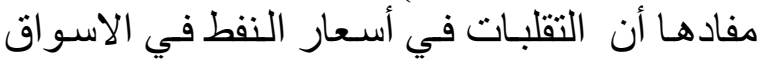

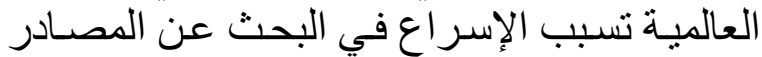

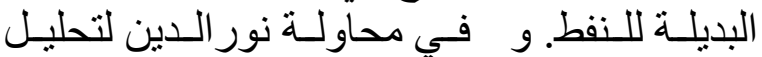

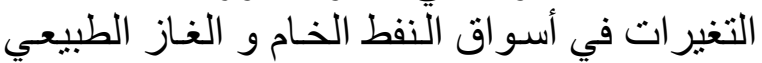

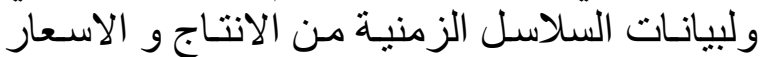

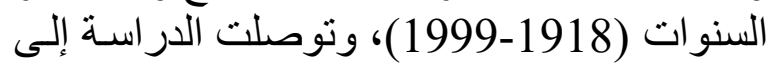

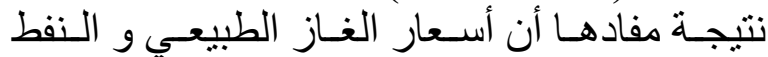


وكلهـا عو امل تتظـافر لتبـاطؤ النشـاط الاقتصـادي.

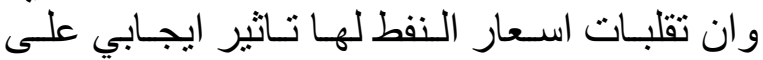

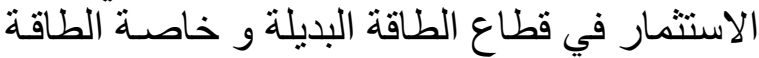
البديلة النظيفة و كذلك فهار فالنأنثير ايجابي على أسعار

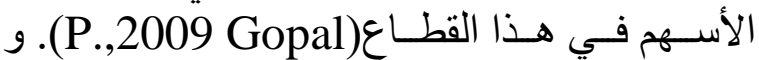
بحث Anthony ايضا دور تقلبات أسعار النفط في

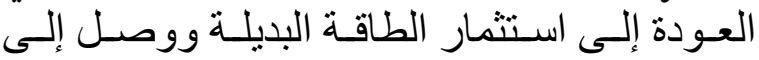

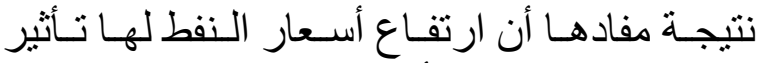

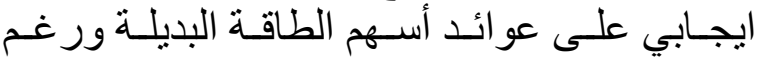
ارتفاع المخاطرة في الاستثمار فيها إلا أن عوائدها النها

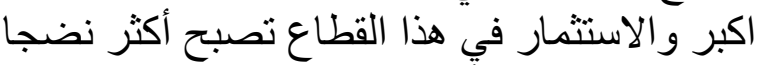

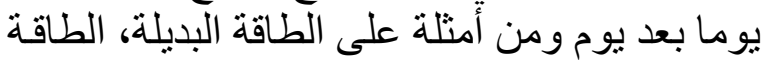

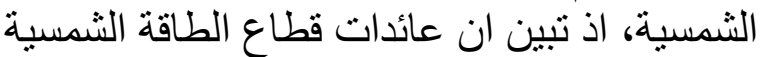

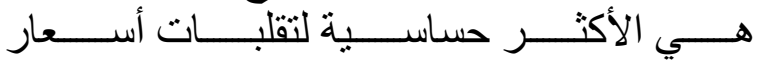

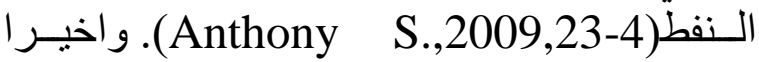
توصـل (Rumi) في در اسـة تناولت اثر تقلبـات أسـعار الـفط على بعض المض المتغيـر ات الاقتصـادية

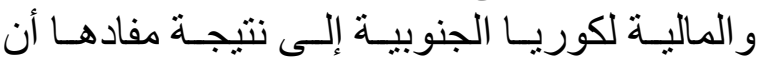
تقلبات أسعار النفط على متغير ات الاقتصـاد الكلي

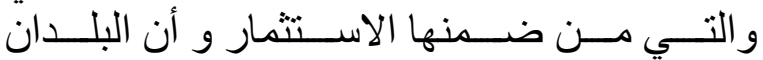
المستوردة الصافية للففط تبحث عن مصـادر بديلـة

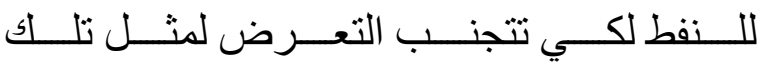

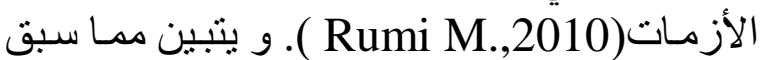

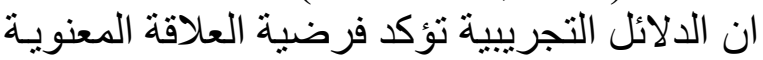

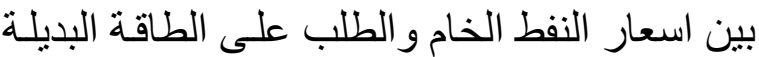

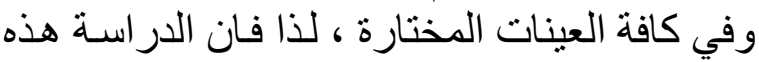

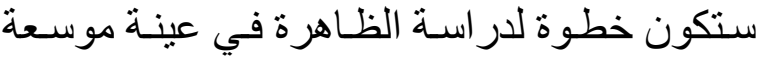

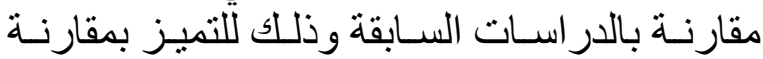
الظاهرة في مختل انحاء العالم. المبحث الثاني:دور مصـادر الطاقة في ميزان الطاقة العالمي:

كان لبدايات ظهور العجز العز في مصـادر الطاقة

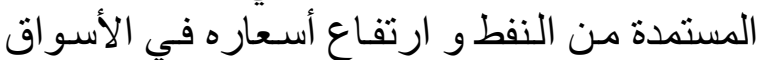

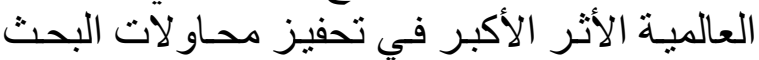

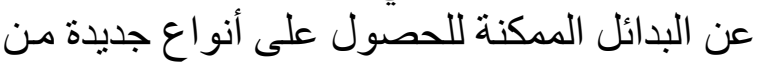

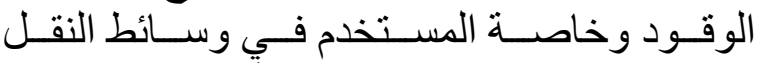

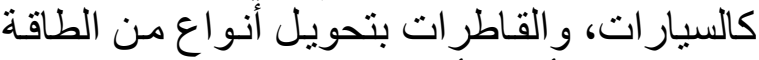

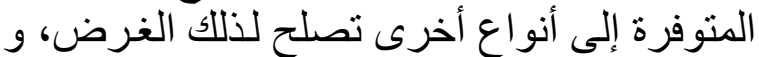

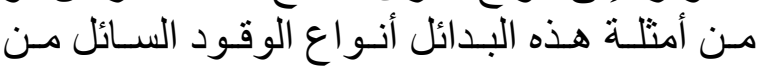

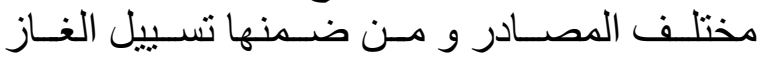

الاقتصادية لهذا البلد، الأمر الذي دعت الحكومـات

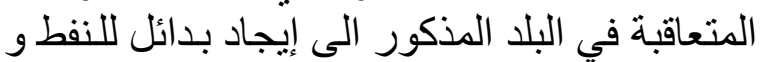

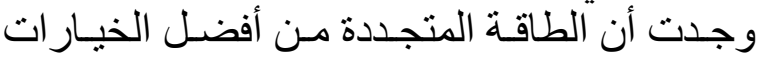

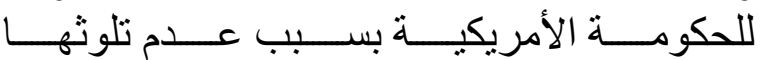
للبيئة (Braml J.,2007,117-30). وفي دراسة حول تأثثر أسعار النفط على أسعار

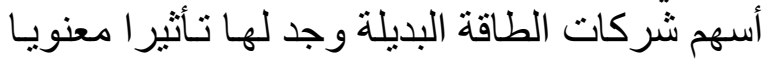

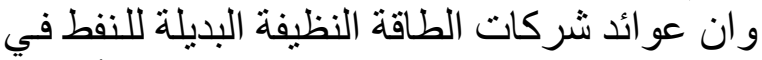
تز ايـــ وذلك بسـبب التقلبـات الحاصـلة في في أسـعار Irene (النفط رغم المخاطر الكبيرة في الاستثنمار و Perry S. \& H.,2008,1009). وتوقع راسل \& Stephen A. H.,2008,322-3) و ستيفان (Russell R. بشكل خـاص على النفط والغـاز الطبيعي بنسبة الطبة الطبة

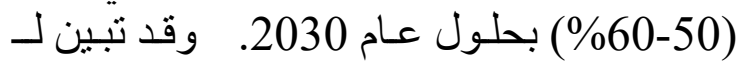
Aron

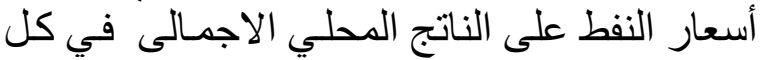

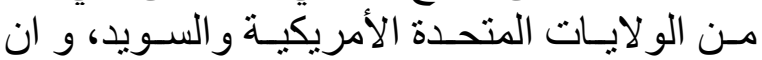

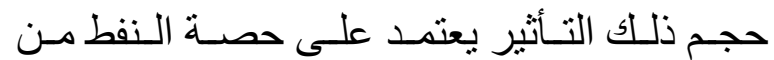
إجمالي الطاقـة المستهلكة في ذلك البلدة، وتوصـا

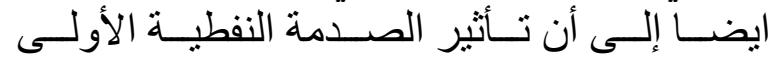

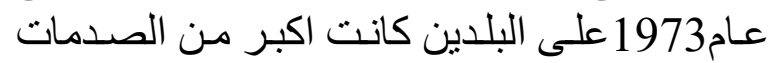

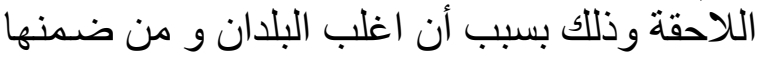

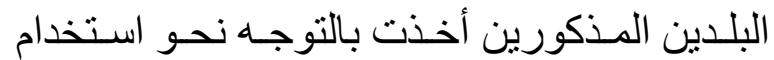
بدائل للطاقة من النفط. وترتب على ذلى ذلك ان تأثير

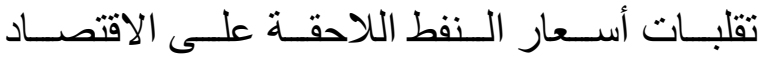

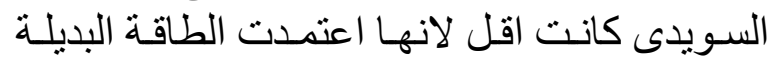

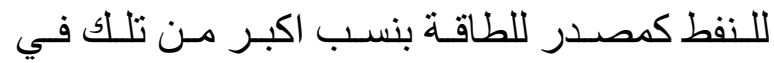

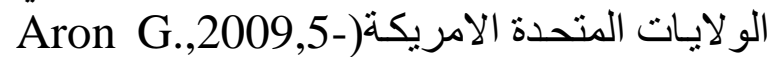
25). وفي در اسـة لـ lin حول العلاقة بين أسعار

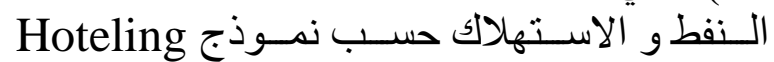

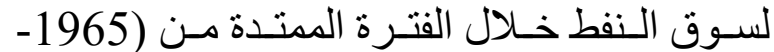

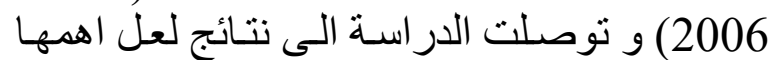

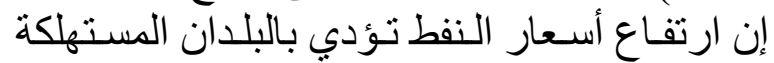

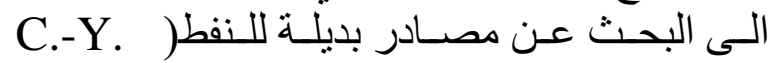
Lin,2009,11-12 حاولGopalG، در اسة أسباب تقلبـات أسعار النفط

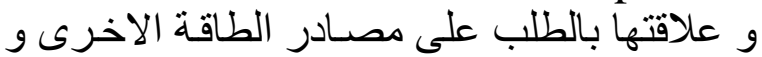

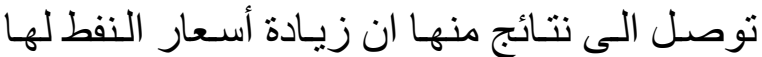

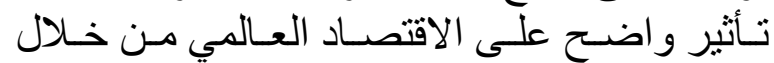

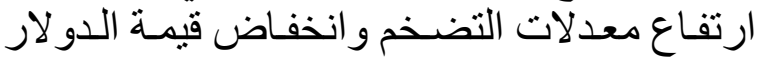


للبلدان الصناعية في وضع سياسـات جديدة للطاقـة الـونة

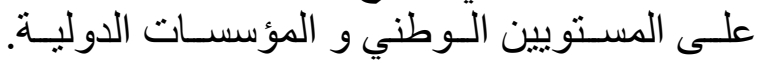

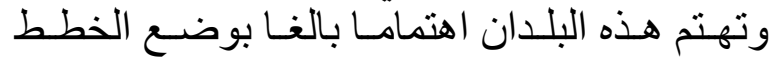

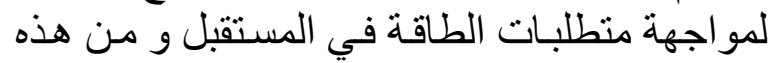

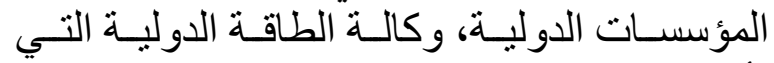

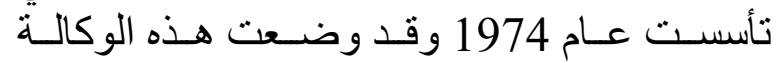

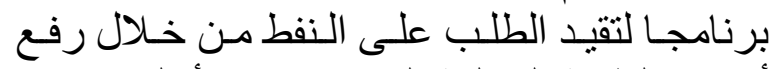

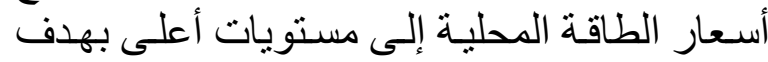

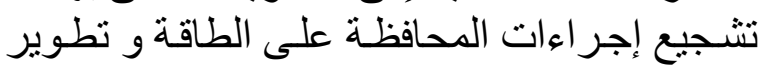

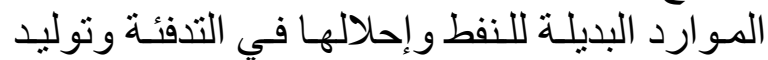

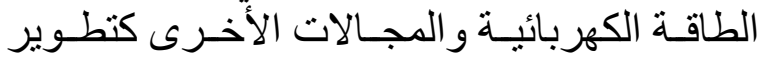

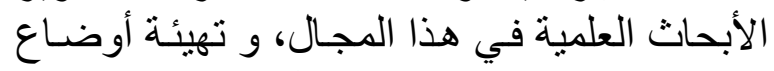

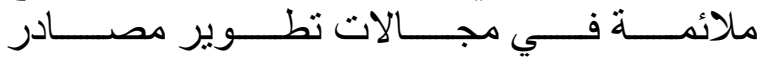

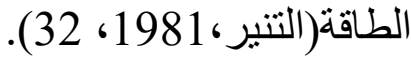
وفي هذا السياق فان البيانات تشير إلى أن الغاز

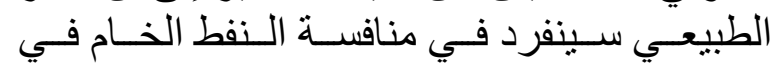

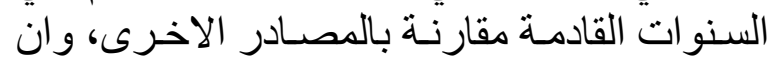

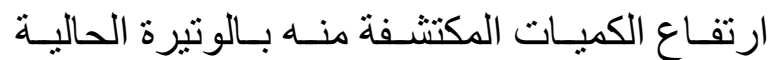

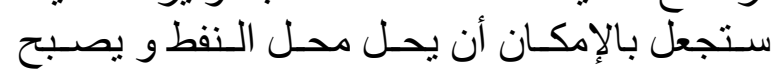

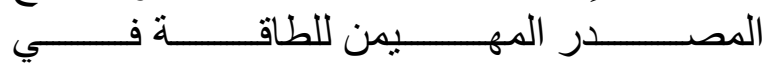

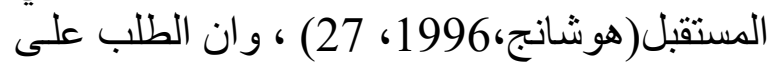

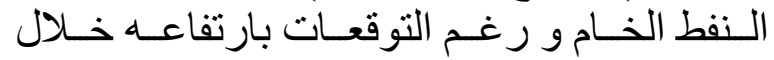

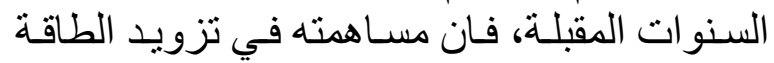

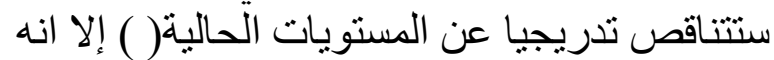

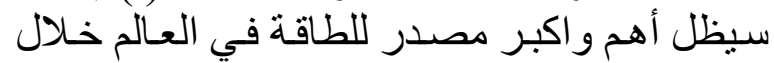

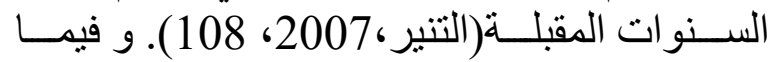

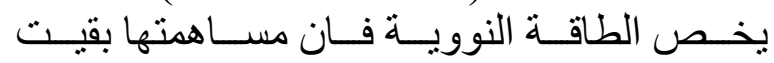
متو اضعة، ر غم أنها ازدادت من (1)

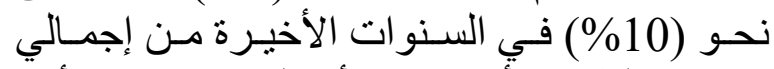

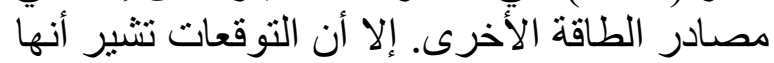

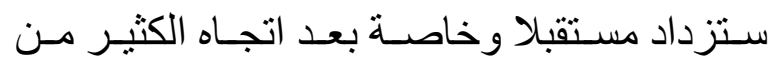

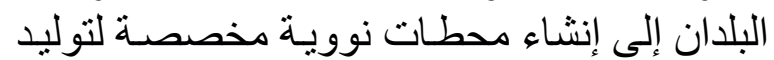

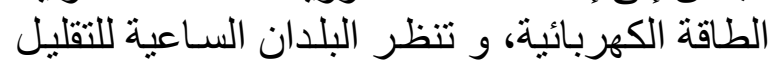

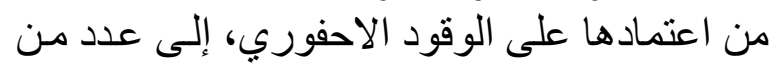

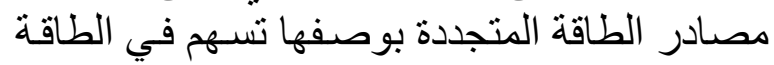

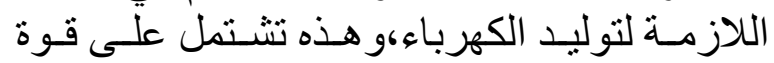

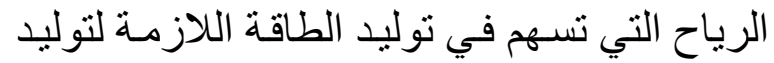

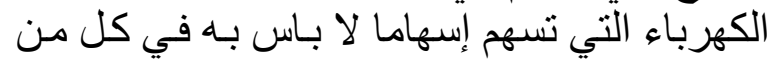

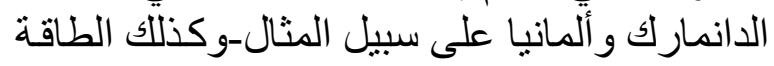

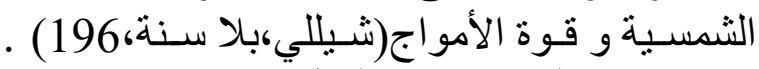
وضمن هذا السياق يمكن القول بان حصـة مصــادر
الطبيعي، وكذلك الفحم الحجري، و إنتاج أنواع من

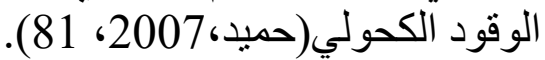
إن مقارنـة الطلب العـالمي للنفط على مصنى مصـادر

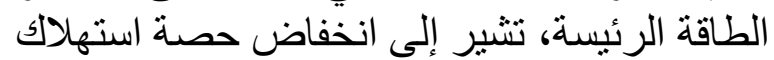

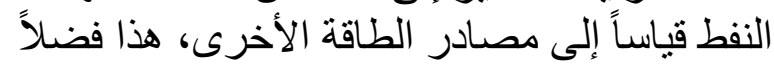

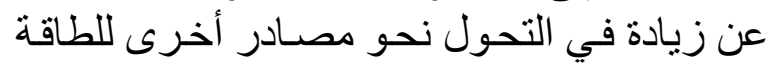

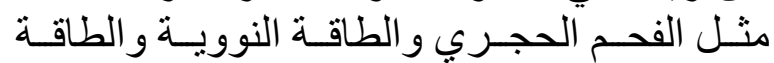

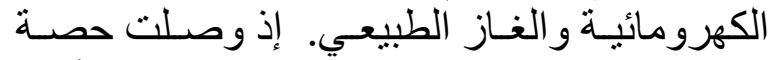
استهلاك النفط من إجمالي مصنادر الطاقة إلى أدنى الدئى

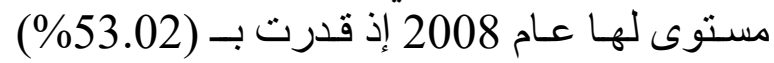
فقط مقابـل (89.16\%) في عـام 1972. و ازداد

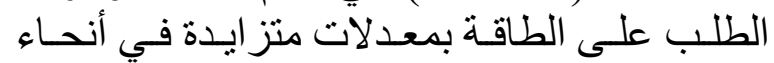

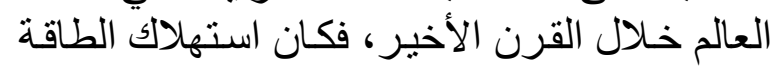

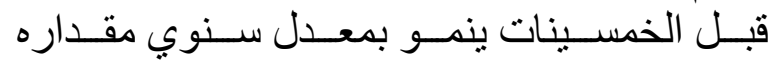

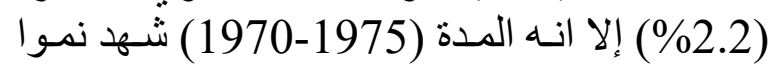

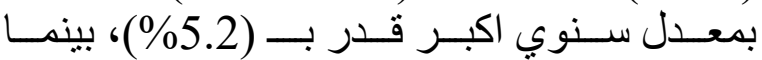
الانخفاض المقدر وبمعدل سنوي مقداره (1970\% (2.3\%)

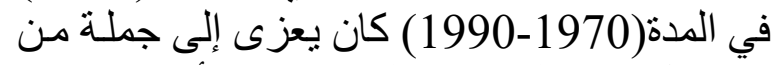

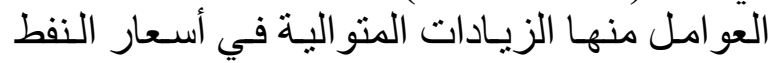

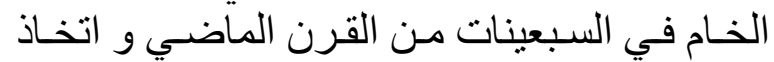

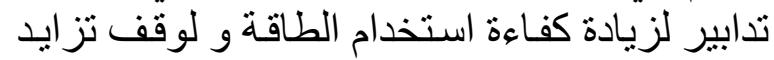

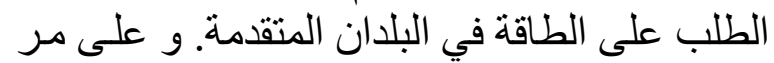

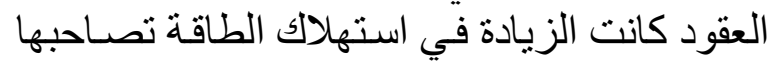

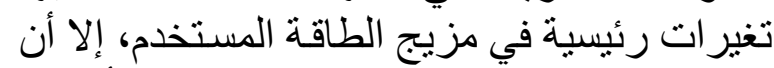

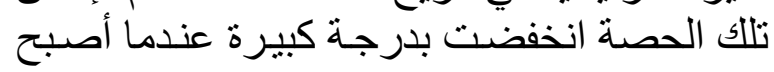

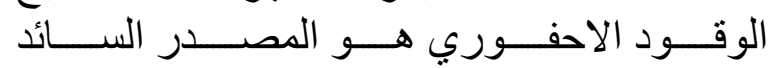

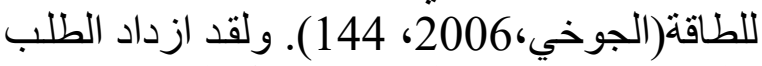

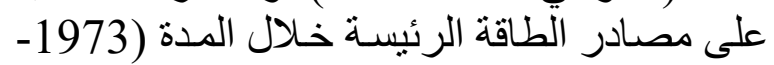

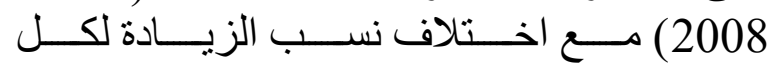

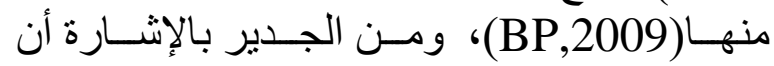

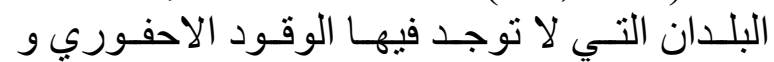
خاصة النفط ستستمر في مشاهدة نمو إنتاج الطاقية

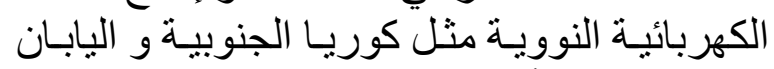

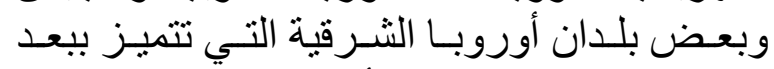

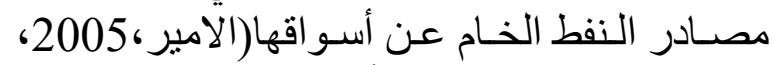

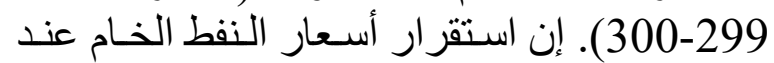

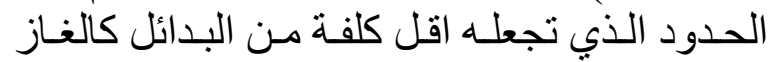

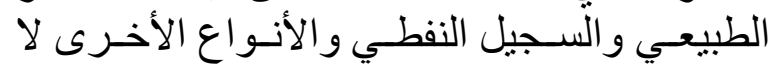

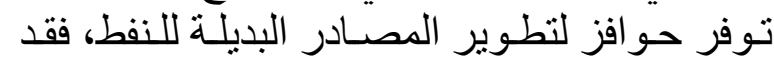

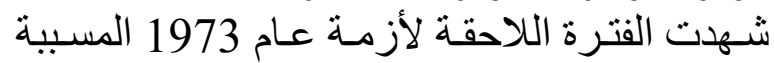
لارتفاع كبير في أسعار النفط الخام محاو لات جادة الفيرة 


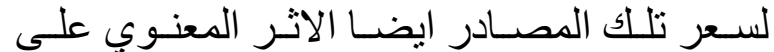

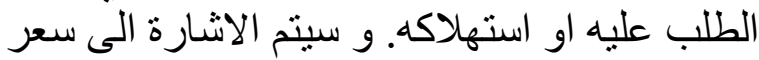
الطاقة البديلة للنفط ب (X)

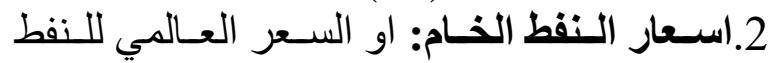

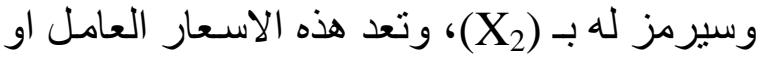

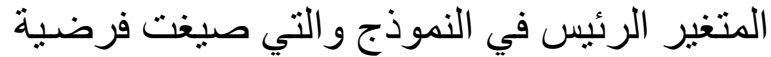
الدر اسة بناء على طبيعة تاثير ها على الطلب فلب على التى الطاقة البديلة، ويتوقع ان يكون للتغير ات فيـه اثر الئا معنويا و كبير ا على التغير ات في المتغير المعتمد،

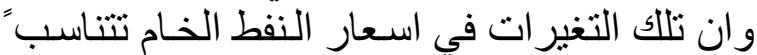

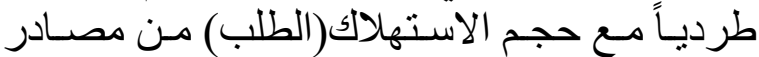

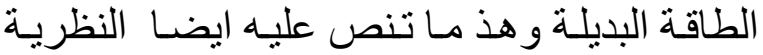

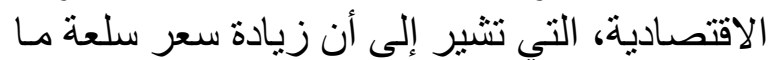
يؤدي إلى انخفاض في حجم الطلب عليها وزيـادة

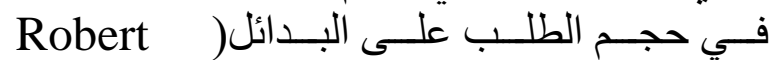

(H.F.,2008,32-33 3.الزمن: لقد استخدم عامل الزمن كمتغير مستقل

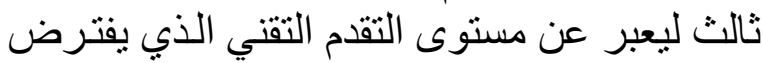
ان بعمل على تخفيض الطلب على النفط من خلانل

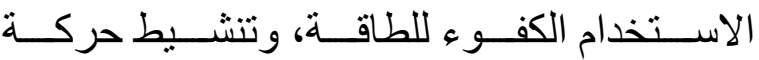

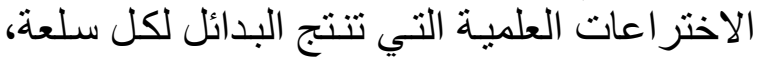

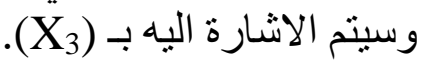

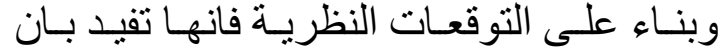

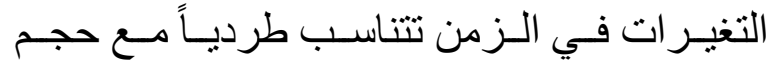

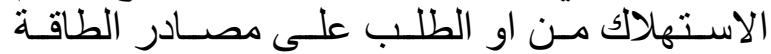

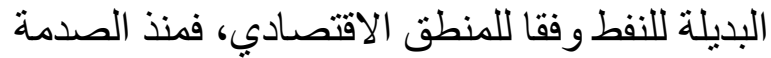

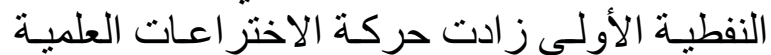

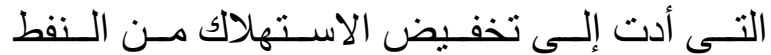

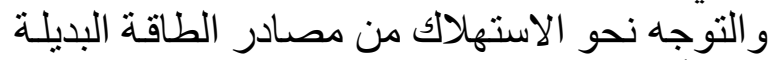

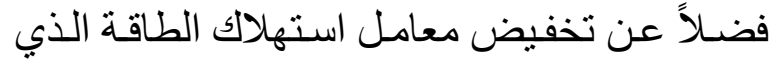
يعبر عن عدد الوحدات اللازمـة مـن الطاقـة لإنتـاج

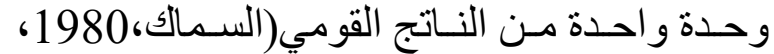

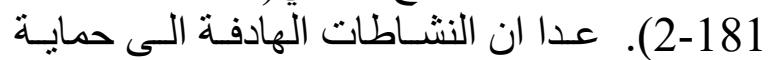
البيئة تدفع الجهود العالمية بهذا الاتجاه.

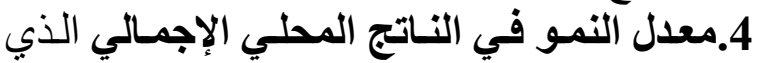

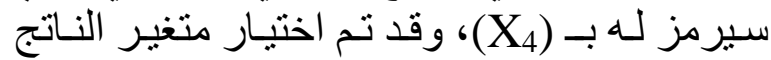

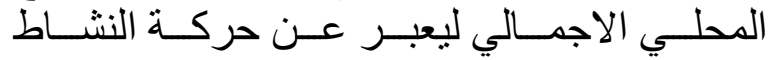

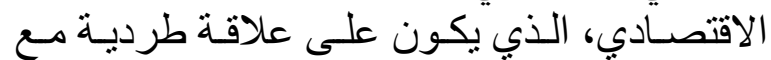
حجم الاستههلاك مـن مصـادر الطاقة البديلـة للنفط

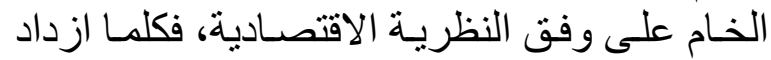

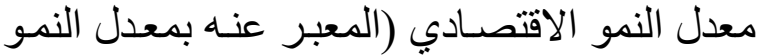

الطاقة في ميز ان الطاقة العـالمي قد شـهـت تطور ا

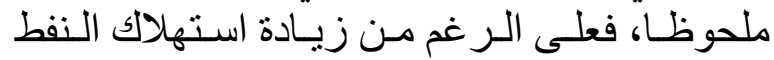
خـلال المدة (1973-2008)، إلا انهه فقد (12\%) من حصته في استهلاك الطاقة في تلك الكدة الكدة فقد تغير نسبتها من(45\%) عام 1973 إلى (34\%)

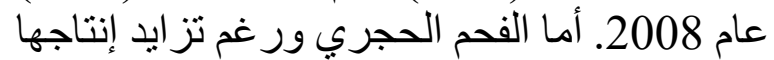

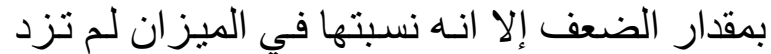

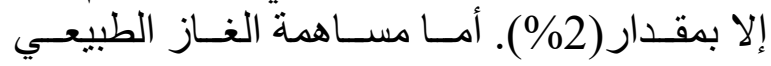

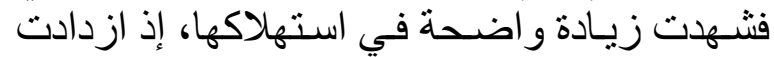
نسبتها بمقدار (5\%) ،و نفس الكسلام يمكن أن يقال

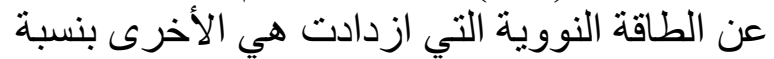

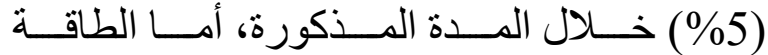
الكهرومائية فلم تزد سوى بنسبة(0.4\%).

\section{المبحث الثالث : توصيف النموذج والنتائج}

للوصول الى نتائج اكثر موضوعية و وائه

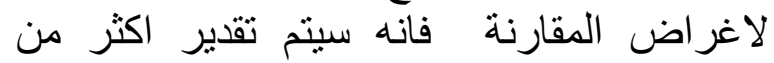
نموذج بناء على تقسيمات لمناطق و اسواق مختلفة الفاته في انحاء العالم وهي|(الولايات المتيات التحدة الامريكية/

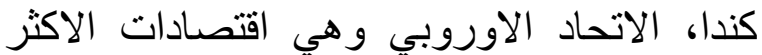
استهلاكا للطاقة، الصين والهين والتيد باعتبار هما دول

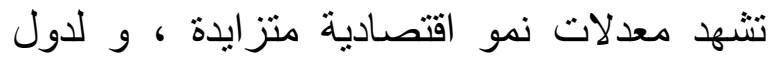

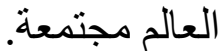
بداية لابد من الاشـارة هنـا ان النمـوذج القياسـي

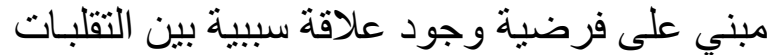
في أَّعار النفط الخام و الطلب على مصدادر الطاقة

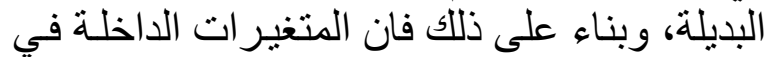
النموذج ستتحدد كالاتي:

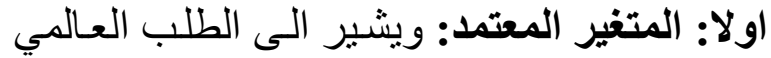

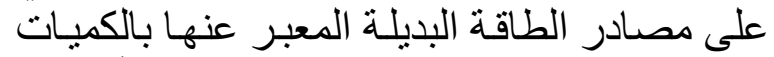

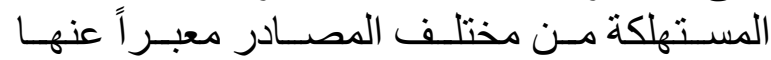

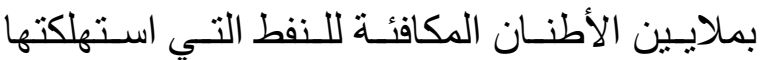

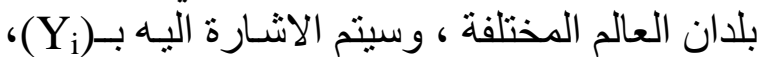

و الذي سيكون دالة لعدد من المتغير ات المستقلة.

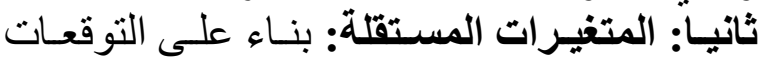
المسبقة للنظرية الاقتصادية و مدى وفرة البيانات

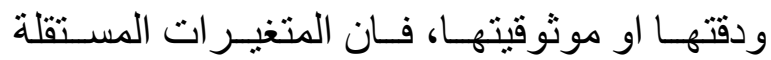

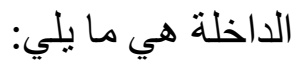

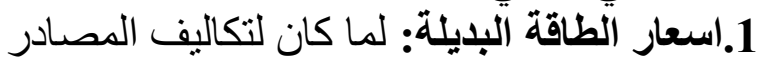

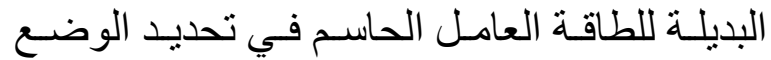

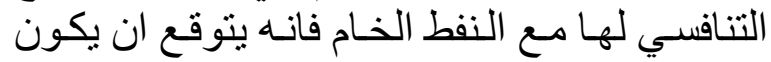




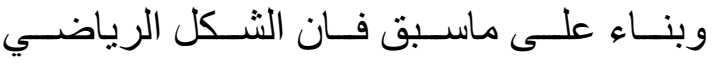

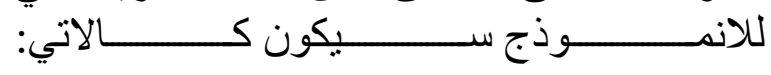

في الناتج المحلي الإجمـالي) أدى ذللك إلى الزيـادة

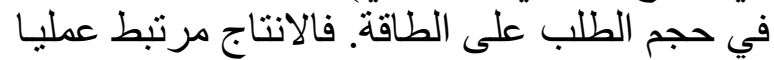

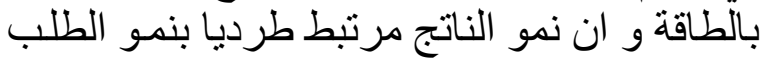
على الطاقة.

$$
\begin{gathered}
\mathrm{Yi}=\mathrm{f}(\mathrm{X} 1, \mathrm{X} 2, \mathrm{X} 3, \mathrm{X} 4) \\
\text { اما الانموذج القياسي فسيتحدد صيغته كالآي } Y_{i}=B_{0}+B_{1} X_{1}+B_{2} X_{2}+B_{3} X_{3}+B_{4} X_{4}+U_{i}
\end{gathered}
$$

\section{المبحث الثاني: تقدير و اختبار النماذج القياسية}

بداية لابد من الاشارة الى انه تم اختبار كافة الصيغ الرياضية المناحة في تقدير الإنة النماذج، و

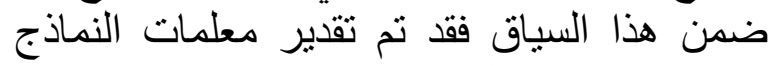

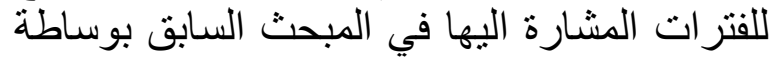

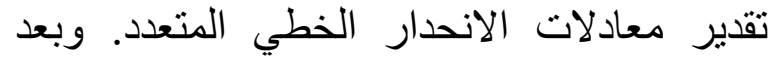

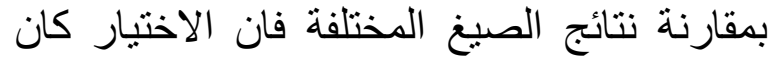

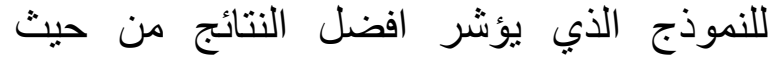
اجتبازه للاختبار ات الاقتصادية و والاحصائية والقياسية. وقد تم إستخدام طريقة المربعات الات الاتية

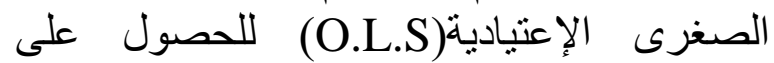
التقديرات المطلوبة، و لهذا الغرض الإن تم إستخدام

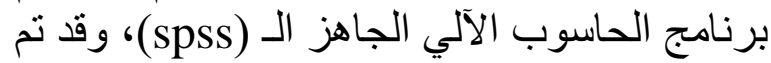
تقييم التقديرات عند مستوى ثقة

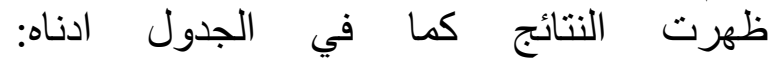

لتشير : التشعi

Bi

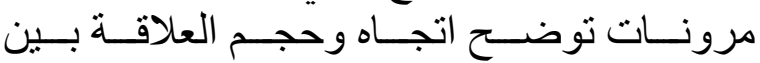
المتغير ات المستقلة و المتغير المعتمد. المداه

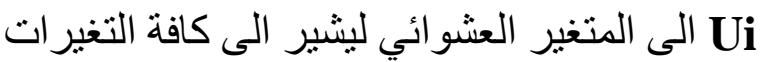

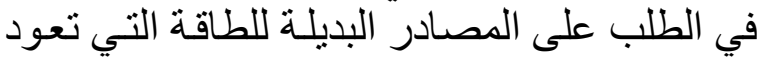
الى عو امل اخرى غير تللك الداخلة في النموذج الطي.

مصادر البيانات و عينة البحث: تم الحصول على البيانات مـن مصـادر مختلفـة،

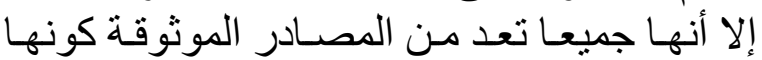

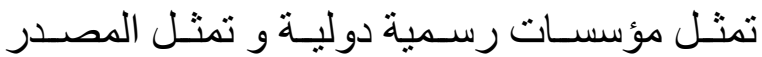

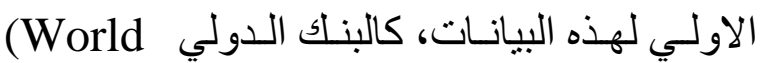
( British وشركة بريتيش بتروليوم، Bank) (Petroleum)، و ومنظمة أوبك (OPEC)

\begin{tabular}{|c|c|c|c|c|}
\hline الدولة او الاقليم & المتغيرات & المعاملات & اختبار (t) & الاختبارات القياسية \\
\hline \multirow[t]{5}{*}{ الاتحاد الاوروبي } & Constant & 2.88 & 19.5 & $\mathrm{R}^{-2}=62.2$ \\
\hline & $\mathrm{X} 1$ & $(0.19)$ & $(1.01)$ & D.W. $=0.808$ \\
\hline & $\mathrm{X} 2$ & 0.784 & 3.58 & \\
\hline & X3 & 0.24 & 1.7 & \\
\hline & $\mathrm{X} 4$ & 0.217 & 1.7 & \\
\hline \multirow[t]{5}{*}{ امريكا الثمالية } & Constant & 1109.61 & 35.93 & $\mathrm{R}-2=63.4 \%$ \\
\hline & $\mathrm{X} 1$ & -12.196 & 5.03 & D.W. $=1.36$ \\
\hline & $\mathrm{X} 2$ & 0.7986 & 1.85 & \\
\hline & X3 & 20.4765 & 36.46 & \\
\hline & $\mathrm{X} 4$ & 0.212 & 1.688 & \\
\hline \multirow[t]{3}{*}{ الهند } & Constant & 65.89 & 6.41 & R-2=98.5\% \\
\hline & $\mathrm{X} 1$ & $(4.475)$ & $(5.44)$ & $D W=0.91$ \\
\hline & $\mathrm{X} 2$ & 1.3205 & 9.02 & \\
\hline
\end{tabular}

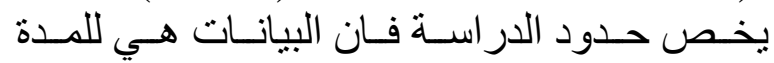
.2008-1973 
مجلة جامعة دهوك، المجلد: 22، العدد: 2 (العلوم الانسانية والاجتماعية)، ص 271-289، 2019

\begin{tabular}{|c|c|c|c|c|}
\hline & X3 & 5.0208 & 24.87 & \\
\hline & $\mathrm{X} 4$ & 0.8156 & 1.52 & \\
\hline \multirow[t]{5}{*}{ الصين } & Constant & 282.855 & 2.91 & $\mathrm{R}^{-2}=95.1 \%$ \\
\hline & $\mathrm{X} 1$ & $(0.20)$ & $(2.96)$ & $\mathrm{DW}=0.580$ \\
\hline & $\mathrm{X} 2$ & 0.556 & 7.37 & \\
\hline & X3 & 0.610 & 10.53 & \\
\hline & $\mathrm{X} 4$ & 0.058 & 1.334 & \\
\hline \multirow[t]{5}{*}{ 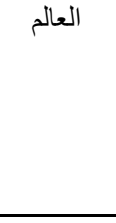 } & Constant & 2.91 & 5.102 & $\mathrm{R}-2=88.8 \%$ \\
\hline & $\mathrm{X} 1$ & $(2.96)$ & $(4.579)$ & $\mathrm{DW}=0.432$ \\
\hline & $\mathrm{X} 2$ & 7.37 & 4.302 & \\
\hline & X3 & 10.53 & 9.315 & \\
\hline & $\mathrm{X} 4$ & 1.334 & 1.374 & \\
\hline$t^{*}=1.684$ & \multicolumn{2}{|c|}{$\mathrm{Du}=1.732$} & \multicolumn{2}{|c|}{$\mathrm{Dl}=1.177$} \\
\hline
\end{tabular}

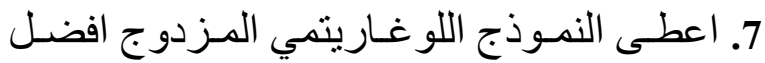

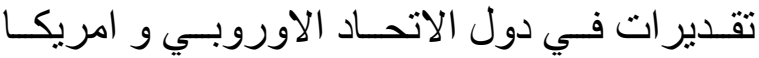

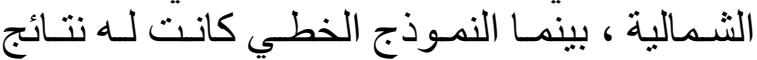

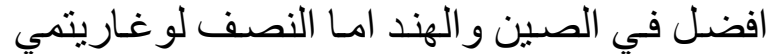
فقد كان الانسب لبلدان العالم مجتمعة.

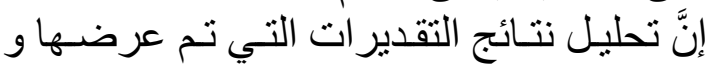
تقييمها وفقا للاختبار ات المشـارة اليها ستتبع نفس تص

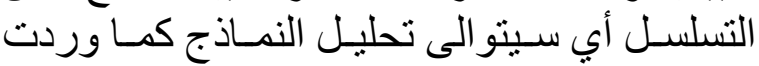
عرضها في المبحث السابق وكذلك تحليل اثر كل

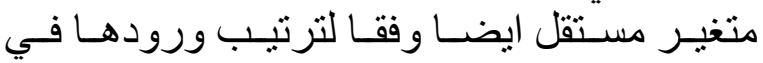

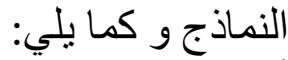

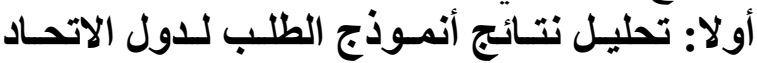

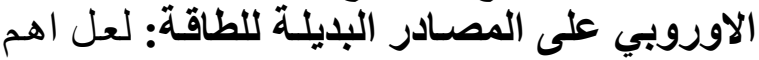

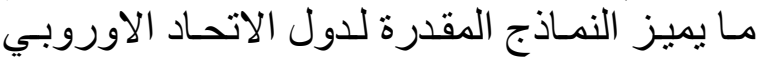
مقارنة بتلك للمجاميع او الدول الاخرى ما يلي: الإني: 1- الانخفاض النسبي لقيمة معامل التحديد المعدل.

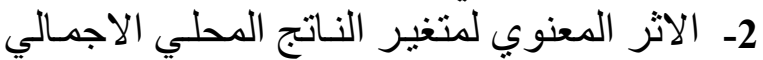
على المصادر البديلة للطاقة.

3ـ عدم وجـود الثر معنوي لاسـعار الطاقـة البديلـة على الكميات المطلوبة منها.

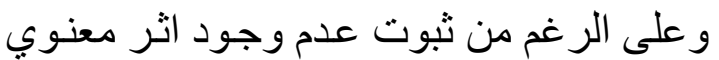

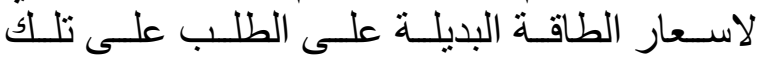

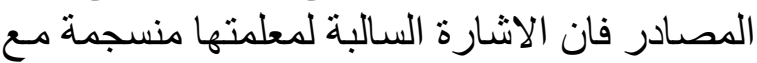

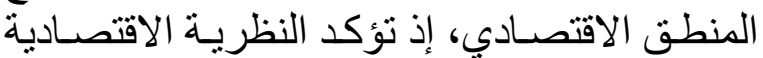

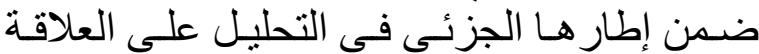

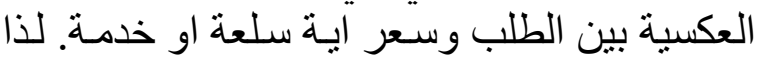
فان الطلب على الطاقة ليست بحالة شـاذة عن بقيـة

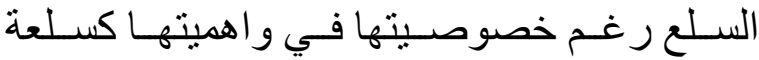
اسـتر اتيجية، وان الاخـتلاف قـد يظهر في حجـم

\section{المبحث الثالث: تحليل وتقيبم التتائج}

بداية لا بد من الاشارة الى ان اهم مـا ميز كافة

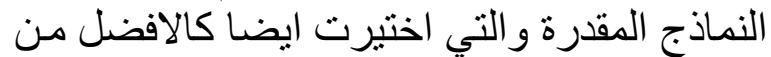

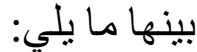
1. ظهرت عدم معنويـة اسعار الطاقـة البديلـة غير

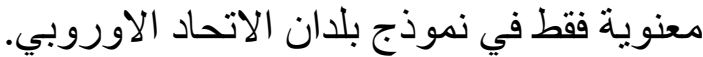

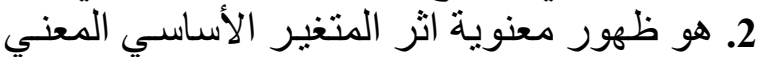
بالدر اسة، ألا وهو التغير ات في اسعار النفط الخـام على الطلب على مختلف المصـادر البديلة للطاقة

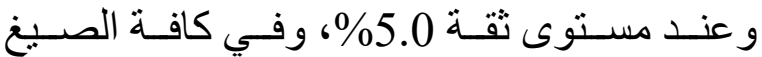

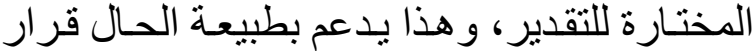
اختياره كمتغير رئيس مؤثز على الطلب البه المثـار

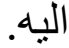

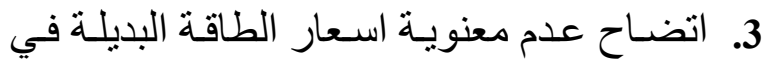

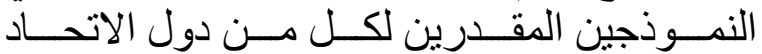
الاوروبي و بلدان امريكا الثمالية.

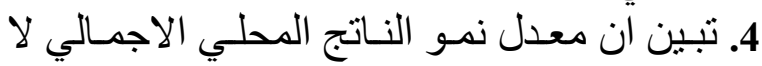

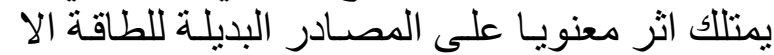

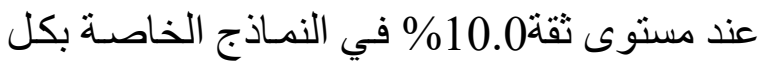
من الهند والصين و النموذج الخـاص بليلدان العـالم

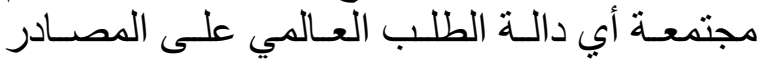
البديلة للطاقة.

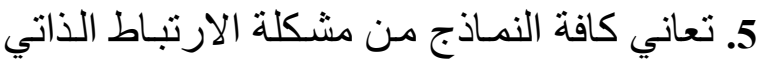
6ين قيم المتغير العشو ائي المتسلسلة.

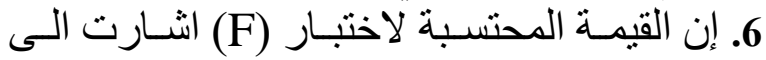

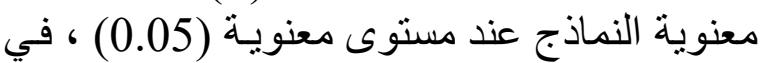

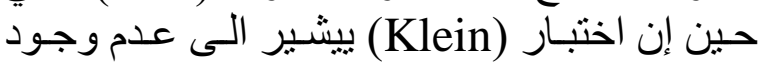
ارتباط خطي بين المتغير ات المستقلة. 


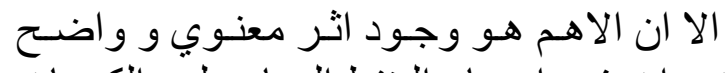

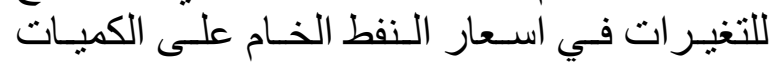

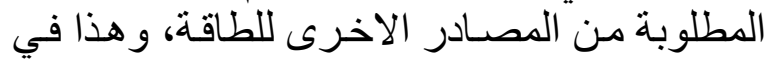

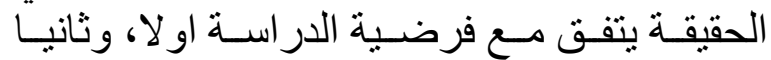

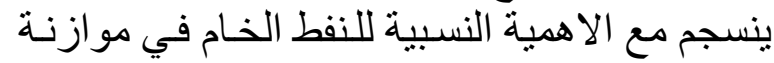

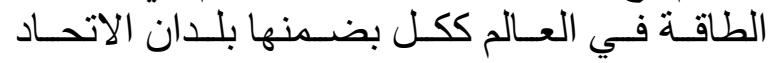
الاوروبي وهذا يعود للاسباب من بينها: 1- الانخفاض النسبي للاسـعار وبالتـالي كلفة النفط لاسنا

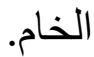

2- توفره بكميات كافية مقارنة بالاحتياجات الدولية للطاقة.

3- ارتفاع الاسعار وبالتالي تكاليف الطاقة البديلة.

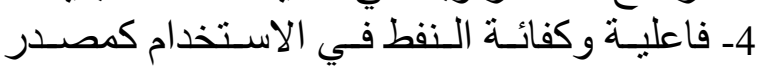
للطاقة

لذا فان التاثير المعنوي لاسعار النفط الخام هو الزها

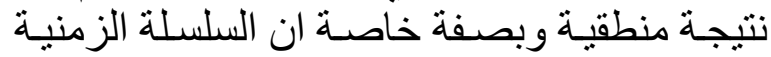

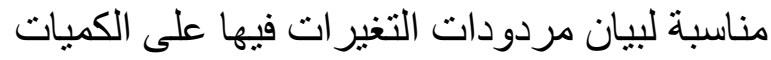

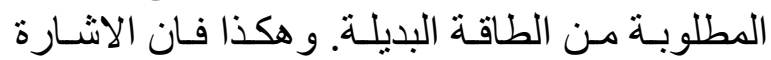

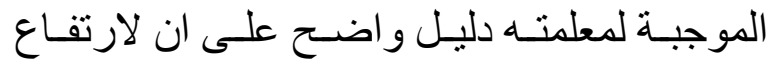

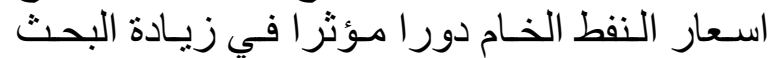

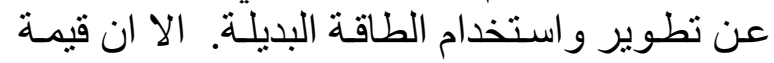

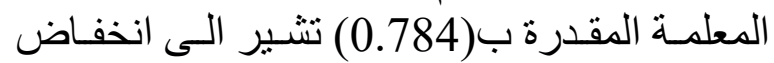

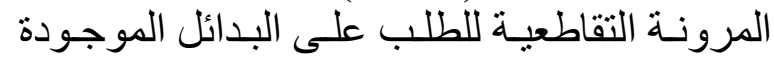

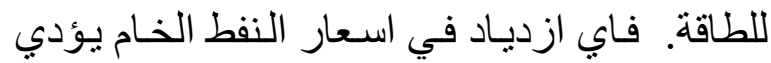

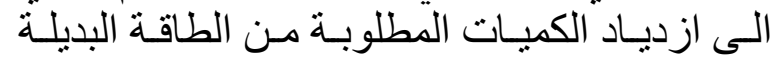

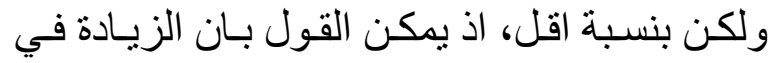

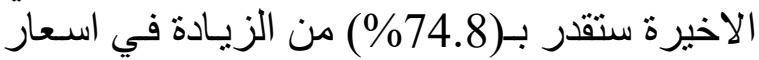

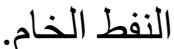

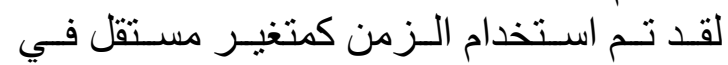

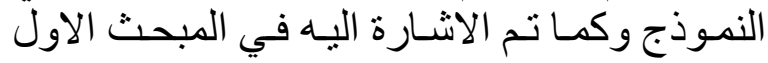
من هذا الفصل لكي يعبر عن مستوى التصدي التقدم التقني الذي يعمل على تخفيض حجم الطلب على على النفط

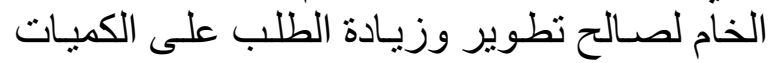

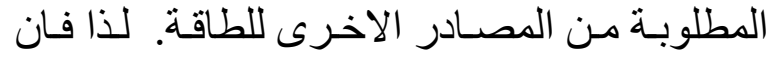
العلاقة الطردية بين هذا المتغير و الطلب الطئ المذكور

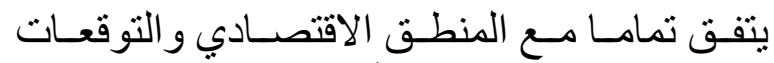

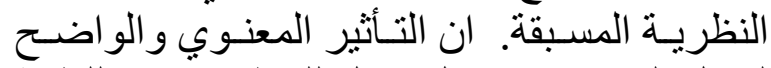

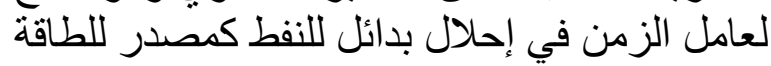
و الارتباط الموجب بينهما يمكن تفسير ها بما يلي: 1- ظهور بدائل متعدد للنفط كمصــادر للطاقة خـالال الفترة المشمولة بالبحث.
المعلمـة التي تشـير الـى المرونـة السـعرية للطلب المبلب على المصادر البديلة للطاقة.

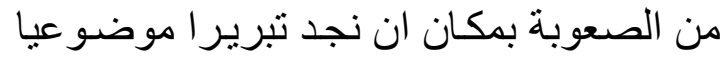

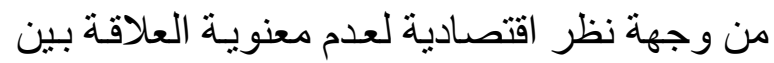

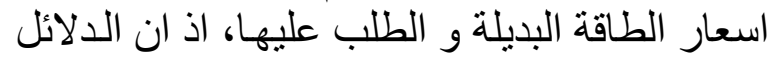

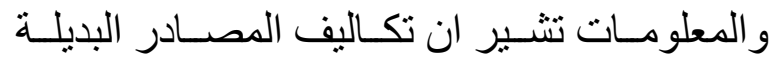

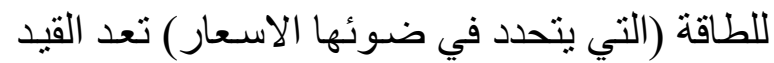

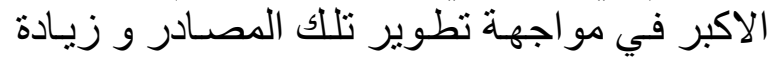
انتاجها، ور غم ازدياد النشاطات الهادفة الهوبر الى تطوير

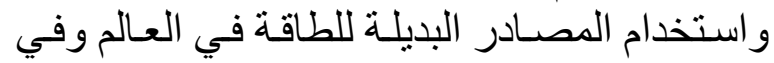

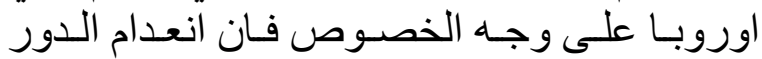

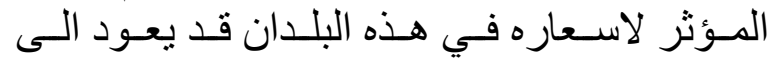

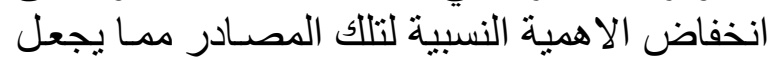
للاسـعار دورا هامشيا او غير مؤثرا في الكئة الكميات

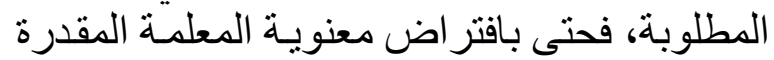

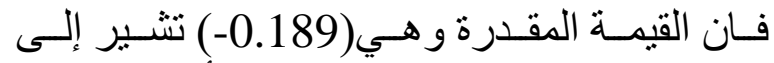

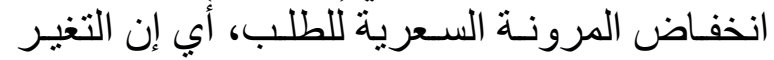

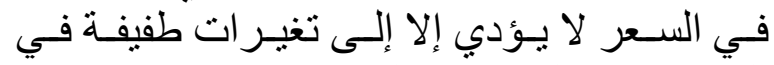

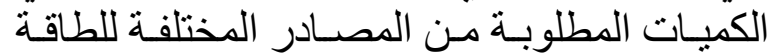

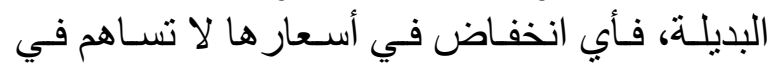

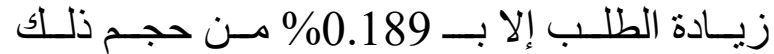
الانخفاض. و ضــن هذا السياق يمكن الاشتـارة الى تبرير

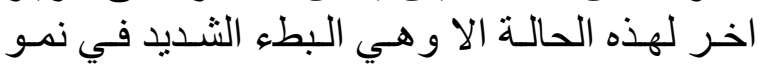

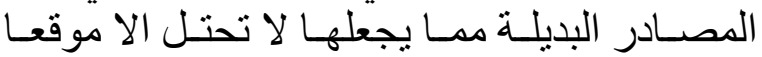

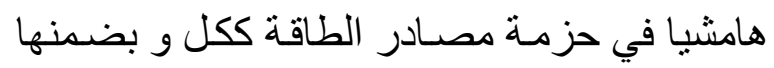

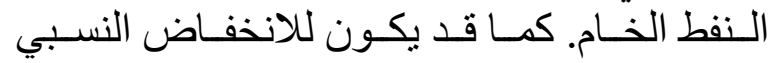

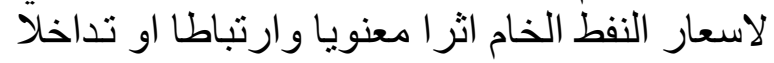

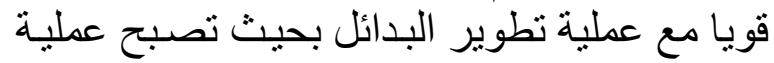

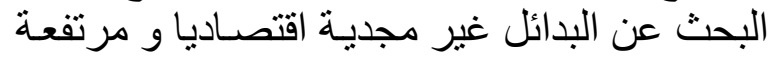

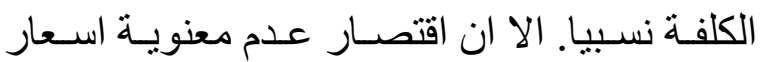

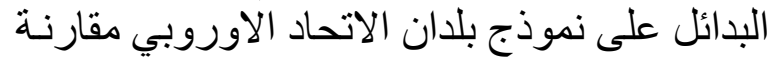

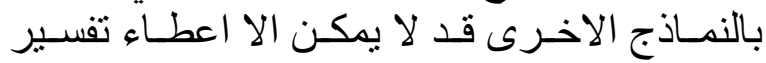

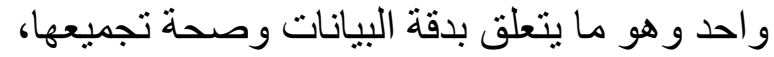
فحتى عند تقدير نموذج يضم متغير استعار البدائل

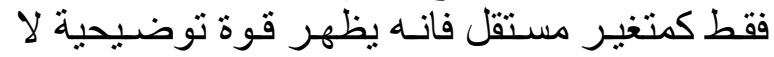

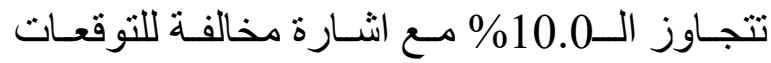

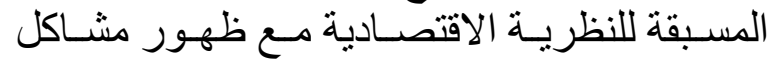

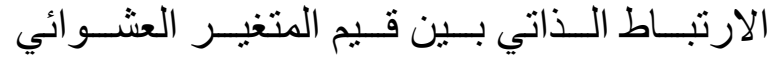

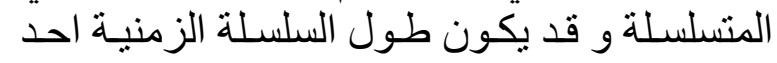
الاسباب الكامنة ور اء ذلك. 
3- ان اسـعار النفط الخـام لاز الت دون الحد الذي أذي

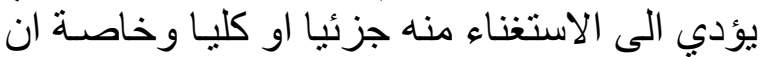

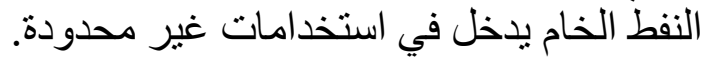

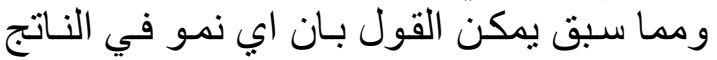

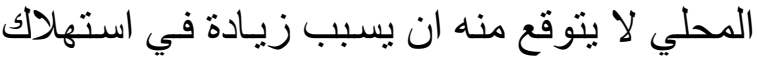

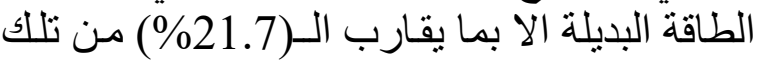

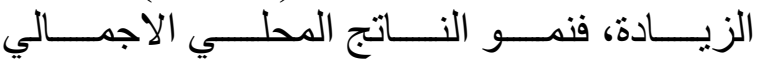

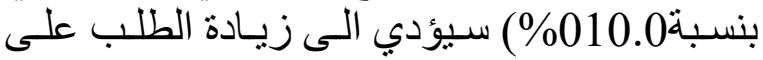

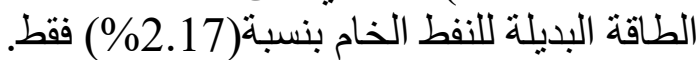

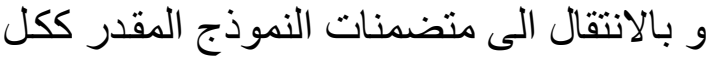

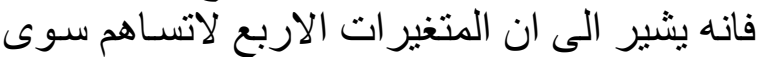

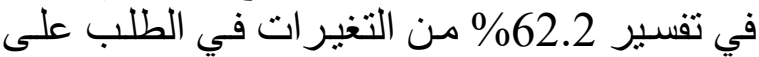

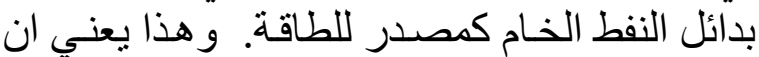

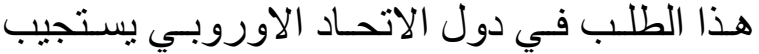

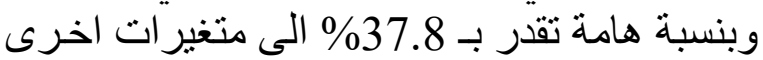

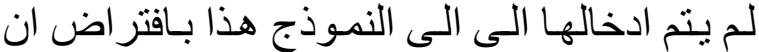

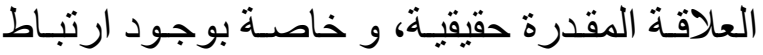

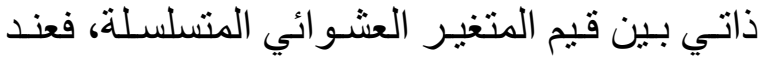

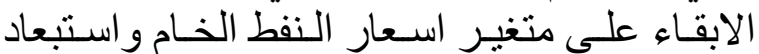

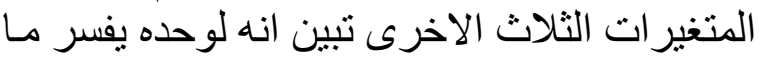

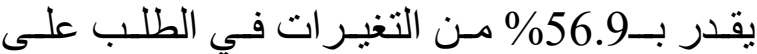

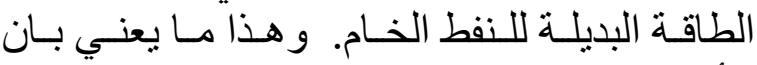

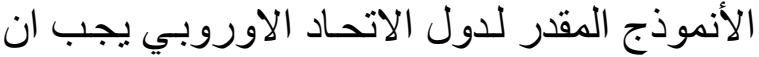
يتضمن متغير ات اخرى اضافية ليكون اكثر توفيقا لأنيا في تفسير التغير ات في الطلب على الطاقة البديلة.

ثنانيا:ـ تحليل وتقييم النماذج المقدرة لمجموعة بلان أمريكا الثمالية:

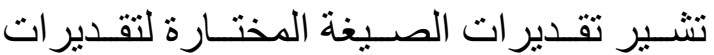

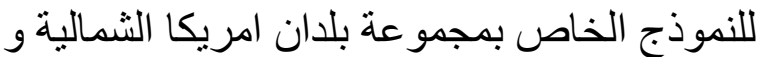

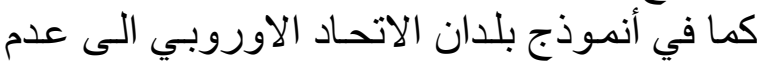

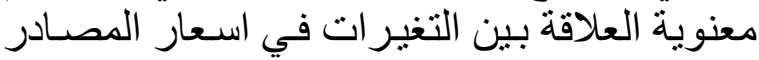
البديلة للطاقة و الكميات المطلوبة منها على التى الرغم غم

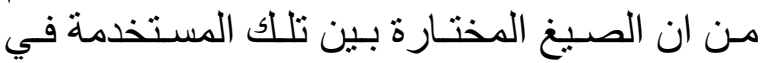

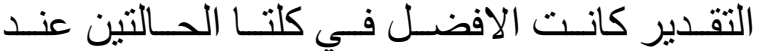

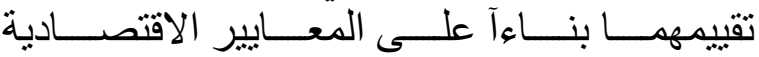

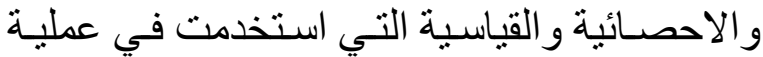

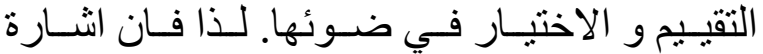

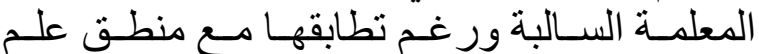

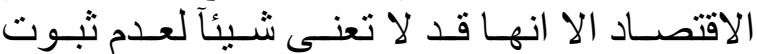

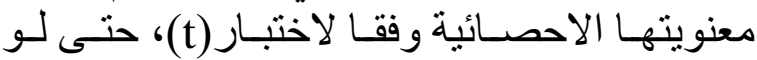
كانت مطابقة للتو قعات النظرية المسبقة.
2- ازديـاد الاهميـة النسـبية لتلـك البـدائل في سـلة الطلب العالمي على الطاقة. 3ـ التغير ات المفاجئة في اسعار النفط الخام.

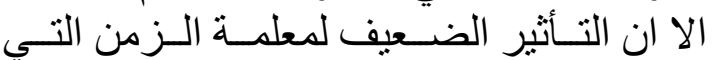
قدرت بأقل من الوحدة الو احدة بكثير (0.24) تشير

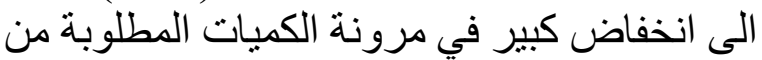

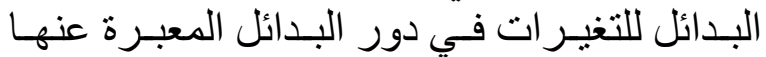

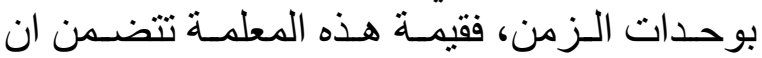

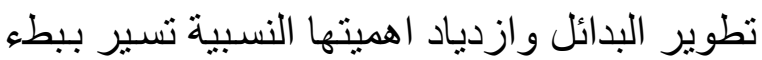

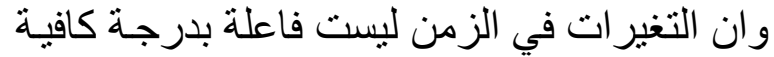

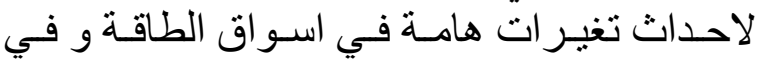
الفترات القصيرة منها او المتوسطة، فابي تغير في

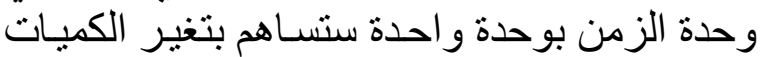
المطلوبة من المصادر البديلة للطاق بــ(0.24)من

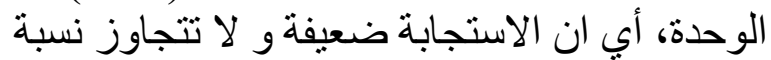
الـ(0.24\%) من التغير ات في الزمن.

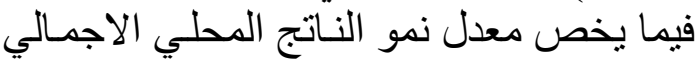

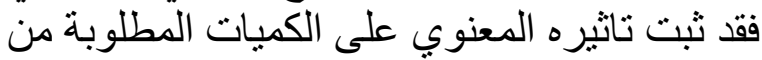

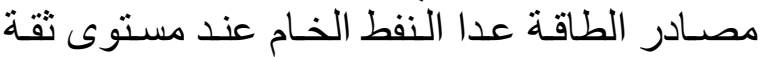

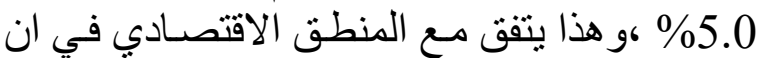

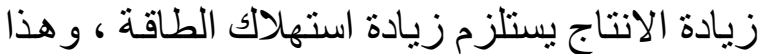

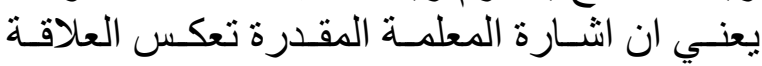

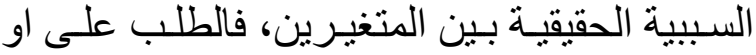

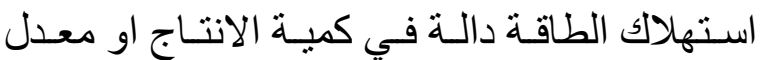

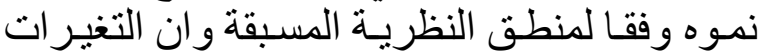

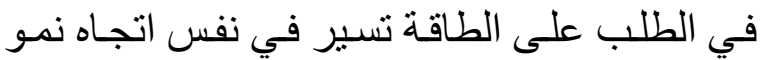

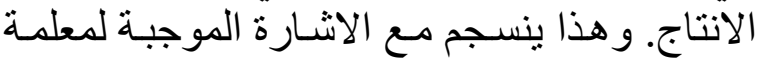

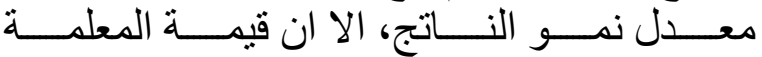

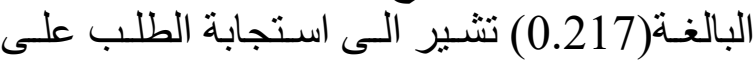
الطاقة الى التغير ات في معدل نمو النـاتج المحلي

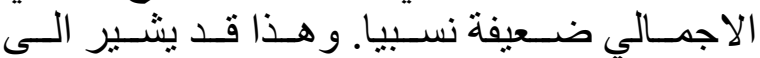
متضمنات مختلفة منه ما يلي:

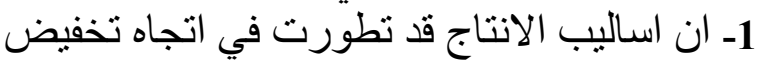

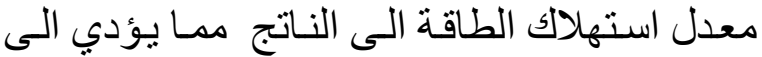

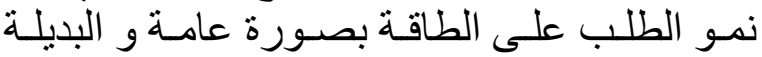

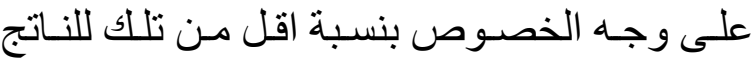

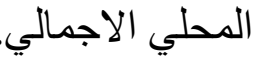

2- ان ارتفــاع أسـعار الطاقـة البديلـة غيـر مغريــة

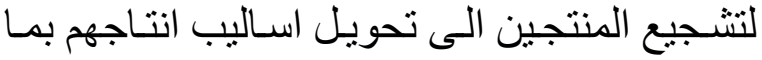
يتناسـب و اسـتخدام المصـادر الاخـرى للطاقـة في لتهي

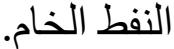


اسعار النفط الخام بنسبة 10.0\% فان الطلب على

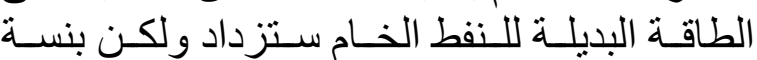
\%7.22 ، و ر رم ذلك فان هذه النسب تشير الى في

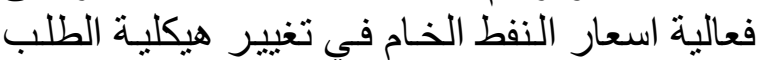

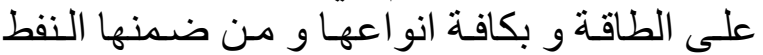

و فيما يخص متغير الزمن بكل ما يتضمنه من فن

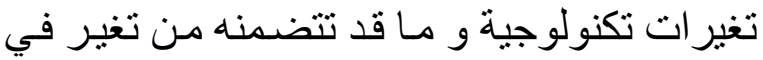

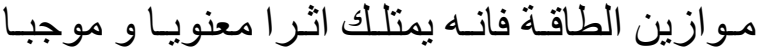

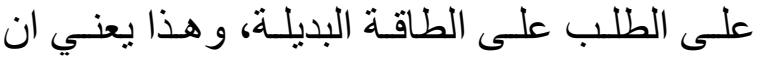

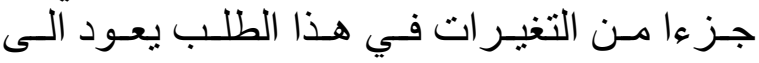

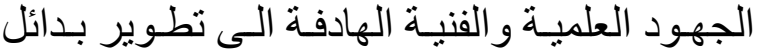

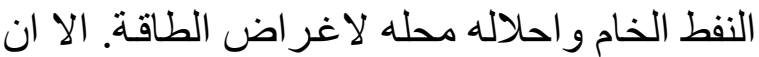

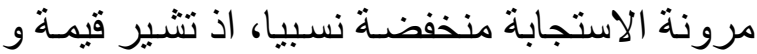

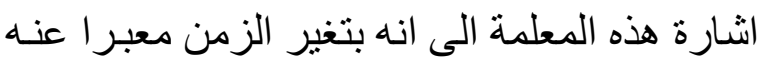

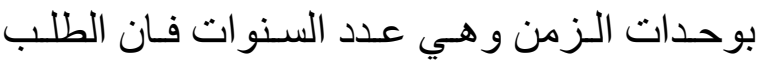

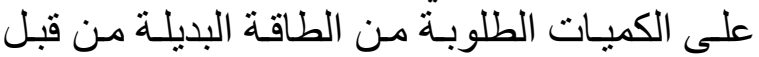
دول امريكا الثمالية سيكون في نفس الاتجاه ولكن من فئن بنسبة اقل. فاذا ما تغير الزمن بنسبة 10.0\%

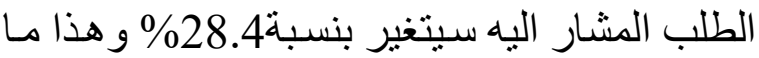

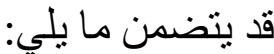

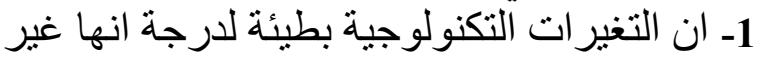

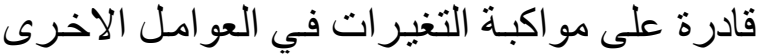

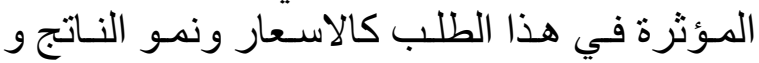

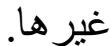
2- ان الكمبات المتوفرة من هذه الطاقة غير كافيـة

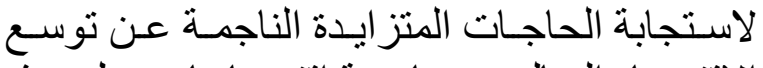

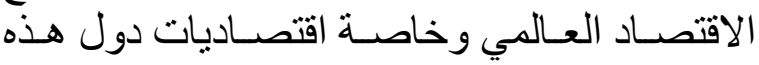

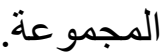

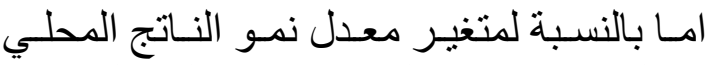

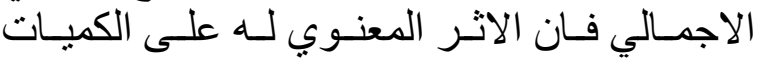

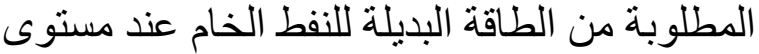

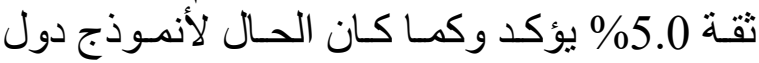

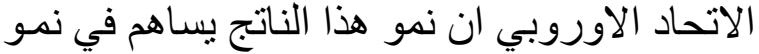

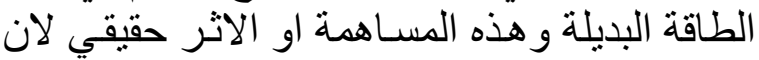

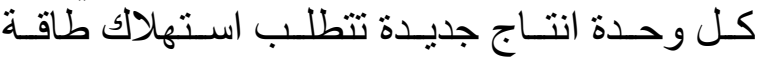

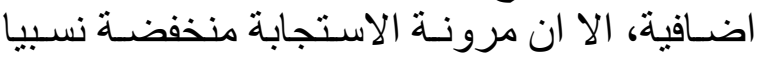
و هذا لا يعني بطبيعة الحال ان الطلب مشبع التبع و انمـا

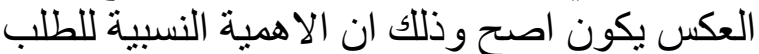

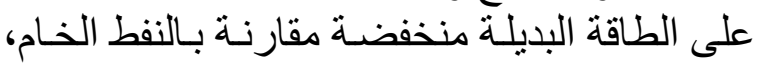

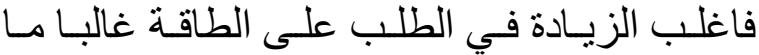

ولمـا كانت هذه البلدان الاكثر استهلاكا للنفط

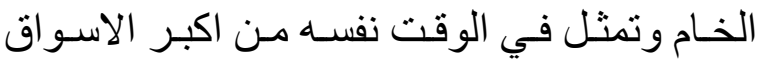

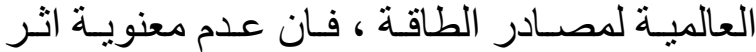

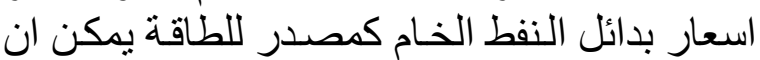

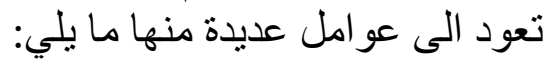

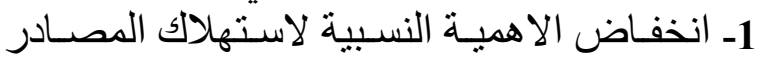

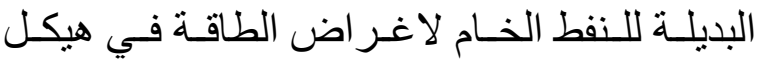
الطلب الاجمالي على الطاقة في هذه البلدان.

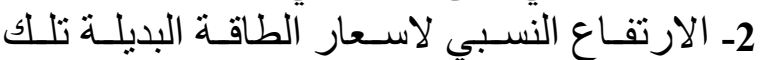

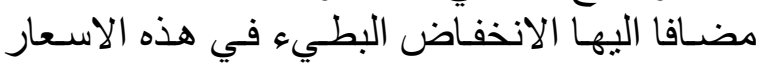

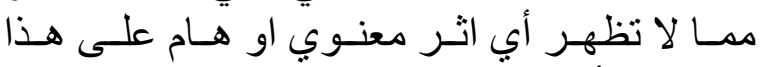

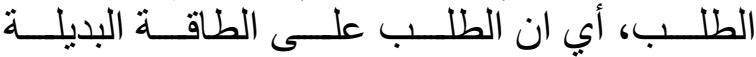

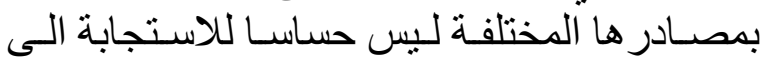
التغير ات في اسـعار ها لحد الان في هذه المجوعة التها

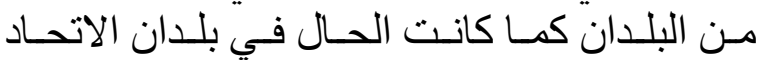

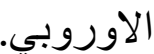

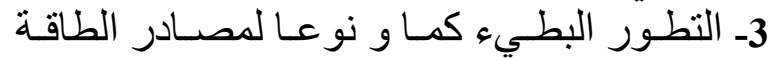

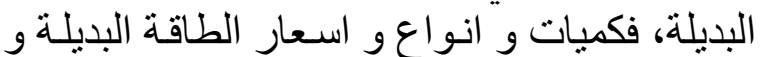
كذلك هيكلية اسواق الطاقة لم تصل الى ألى الحالة التي

تستطيع فيها تهيئة اجو اء المنافسة بين البدئ البيلين.

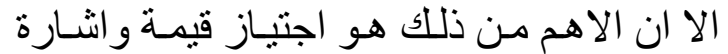

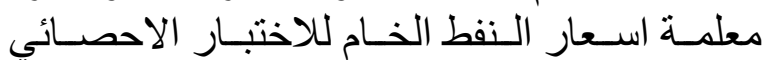

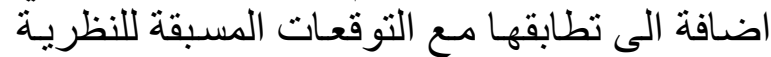

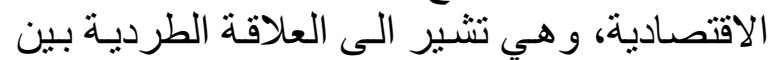

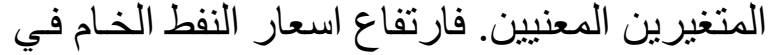

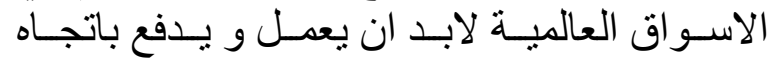

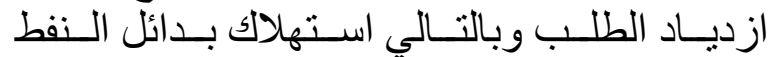
لاغر اض الطاقة وان سلوك كذ هذا الطلب في بلدان

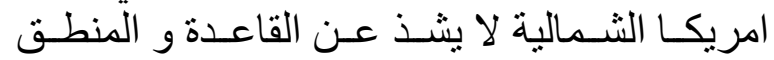
العلميـين الاقتصـاديين. و وككذا فـان هـان المتغيـر

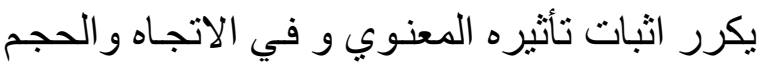
الذي يتطابق مع منطق النظرية الاقتصادية. و و بما

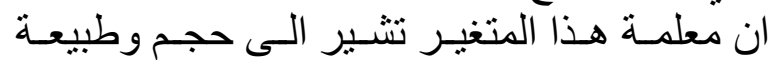

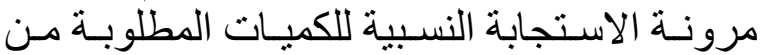

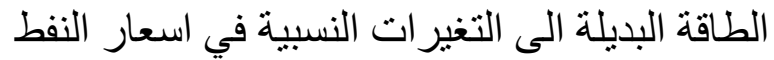

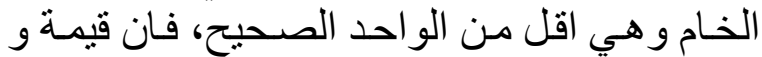

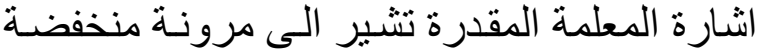
بين المتغيرين و ان أي تغير في اسعار النفط التهير الخام

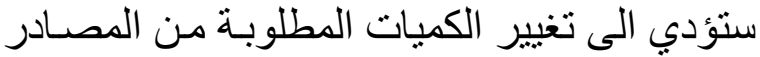

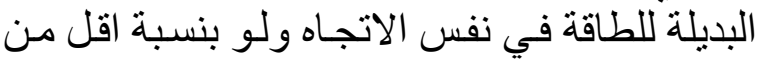

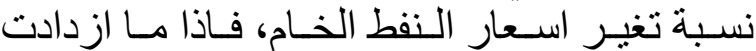




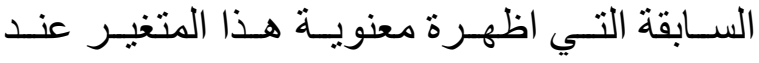
مستوى ثقة 5.0\%

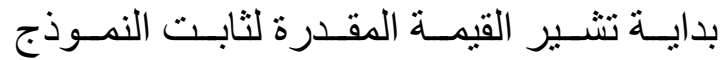

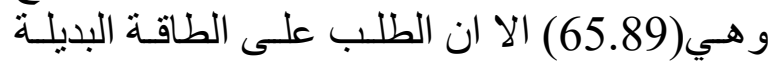

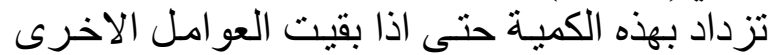

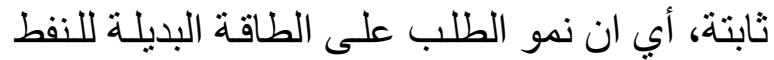

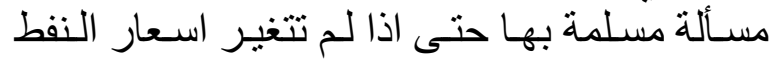

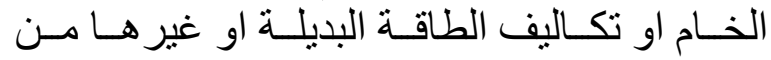
العو امل الداخلة في النموذج. امـا بالنسبة للتغيرات في في اسـعار الطاقـة البديلة

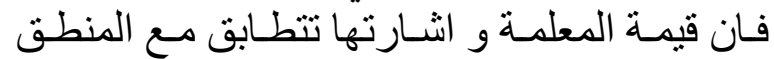

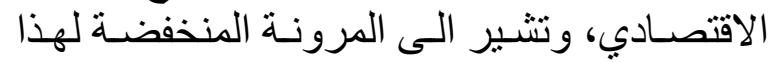

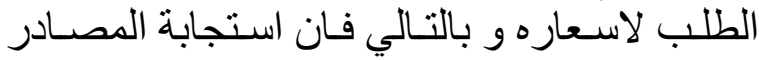

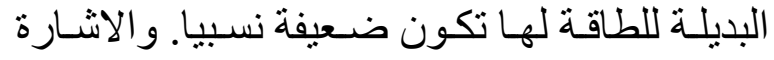

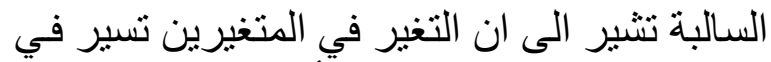

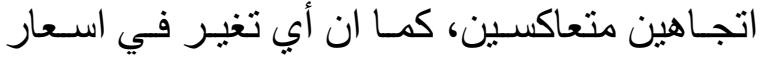

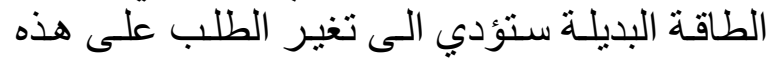

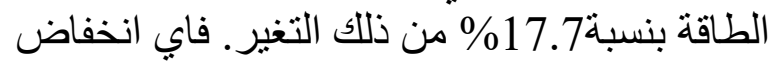

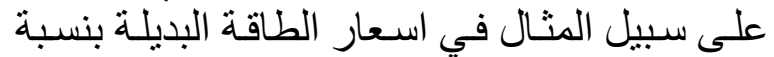
10.0\% سيؤدي الى زيادة الطلب على الثلى تلك الطاقـة

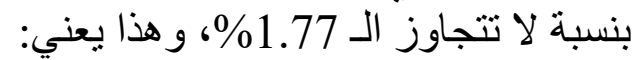
1- ان استجابة الطلب على المصادر البديلة للطاقـة محل النفط الخام يجري بمعدلات بطيئة جدا فيمـا يخص علاقته باسعار ها.

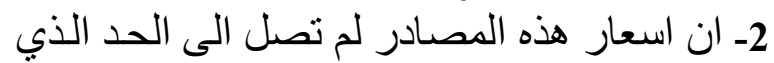

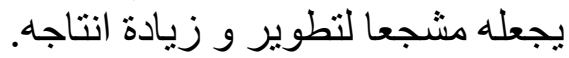

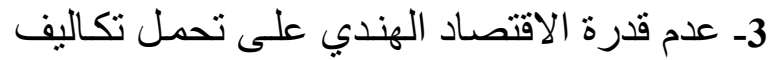
تطوير وزيادة انتاج المصادر الإدياد البديلة.

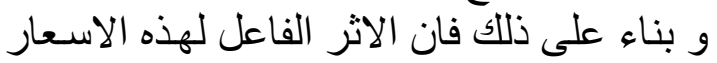

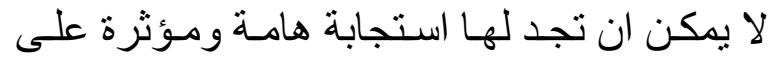

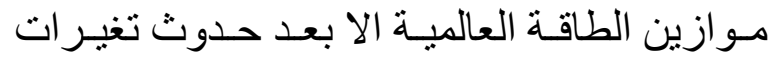

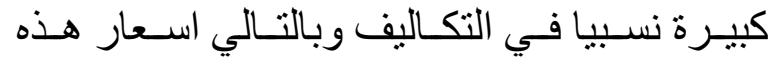

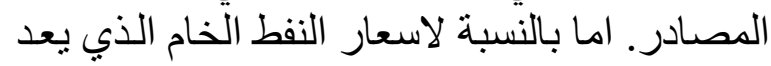

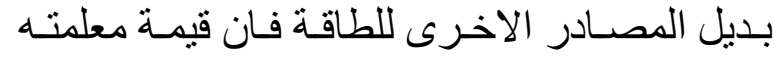

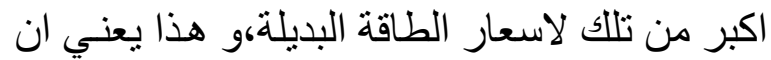

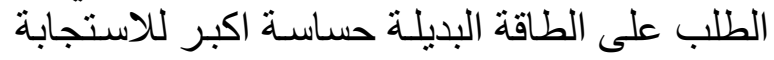

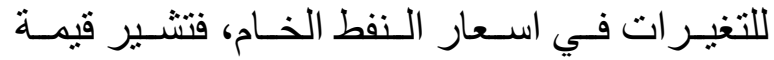

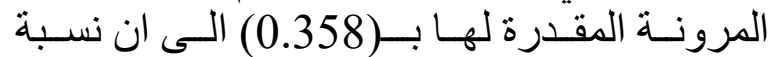

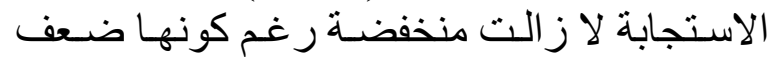

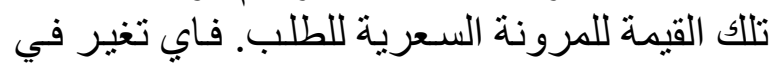

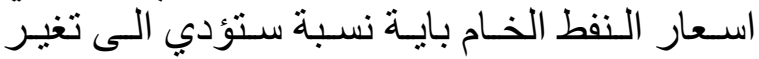

يكون على النفط الخام. اضـافى الى ارتفـاع اسـعار

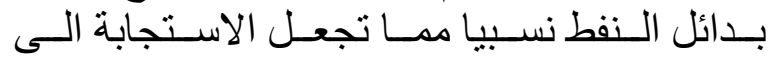

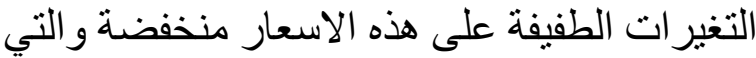

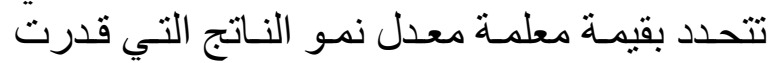

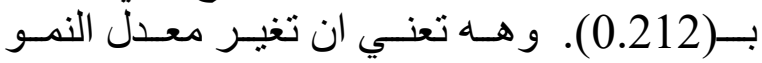

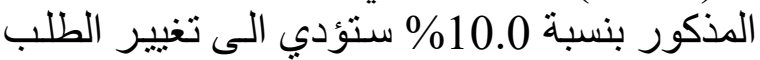
على بدائل النفط لاغر اض الطاقة بنسبة 2.12.

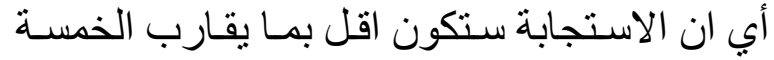

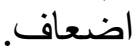

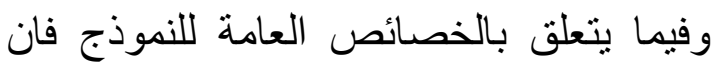

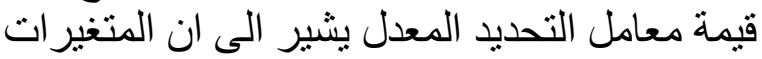

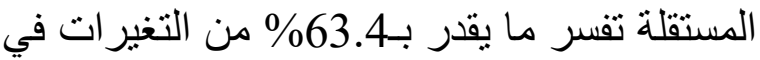

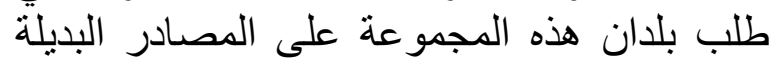

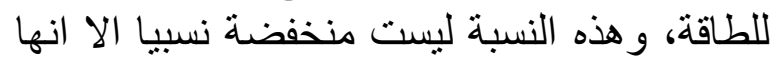

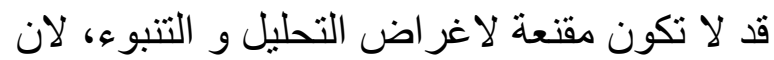

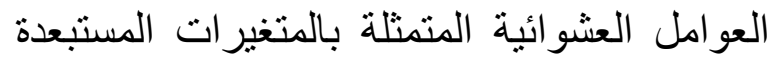

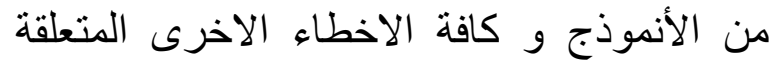

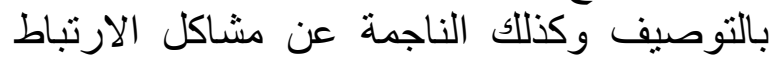
الذاتي والمتغبر الغير المؤثر بشكل معنوي تساهم

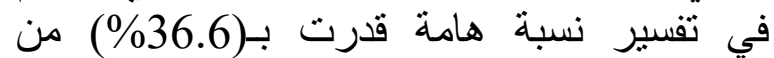
التغير ات الاجمالية في طلب دولة دول امريكا الثمالية عل المصادر البديلة للطاقة.

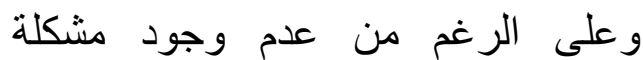
الارتباط الخطي المتعدد بين المتغيرات المبن المستقلة

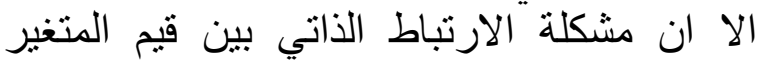
العشوائي قائمة مما تؤثر على الألى القدرة التفسيرية

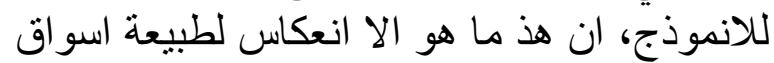

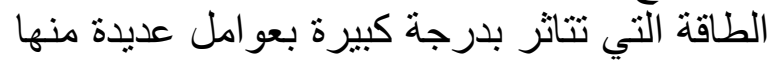

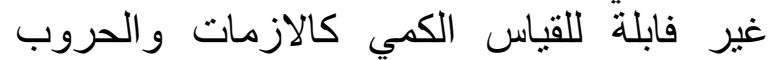

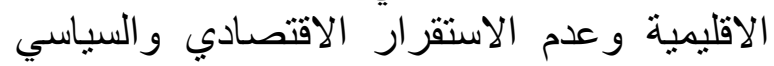

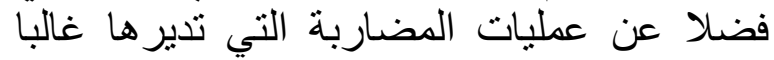
مؤسسات ذو طابع احتكاري. 3-تقييم وتحليل تقدير ات الأنموذج الخاصئ الخاص بالتهند:

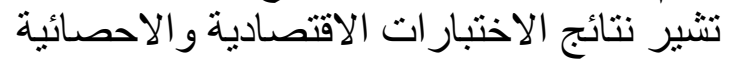

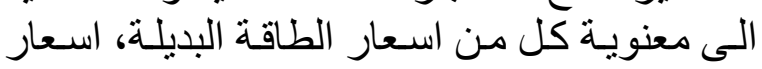

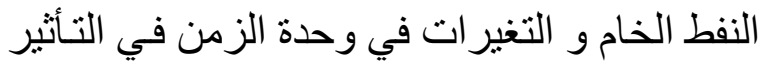

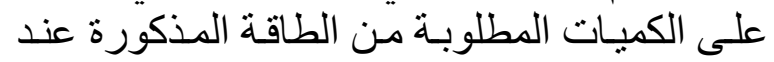

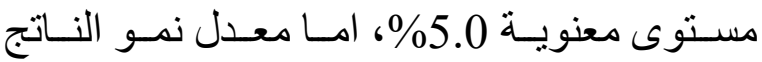

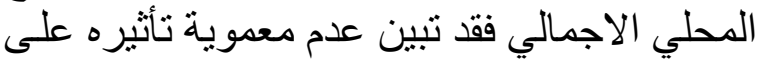

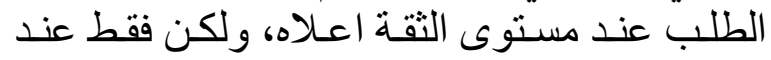
المستوى10.0\% و هذه النتيجة مختلفة عن النمـاذج 
للاسـتجابة الـى الاحتياجـات الفوريـة للاقتصــاد

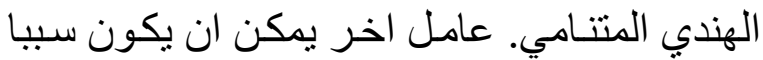

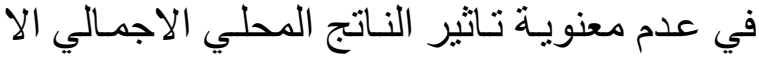

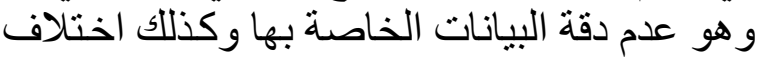

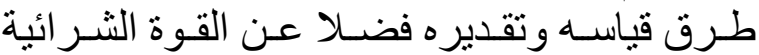

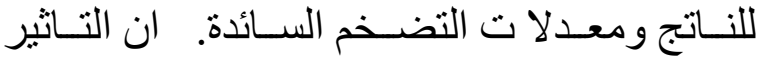

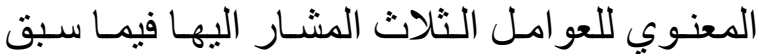

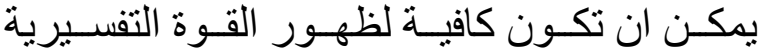

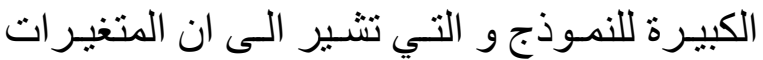

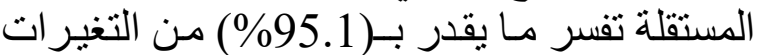

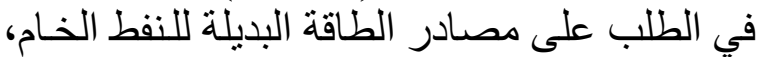

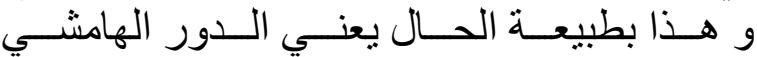

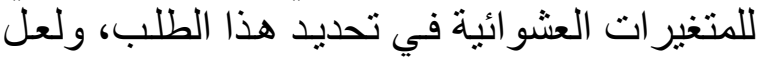

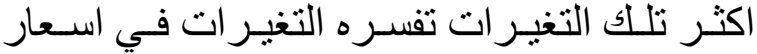

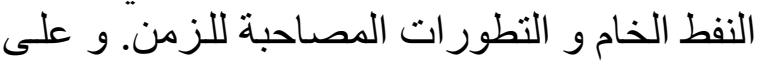
الر غم من وجود ارتبـاط ذاتي بين القيم المتسلسلة

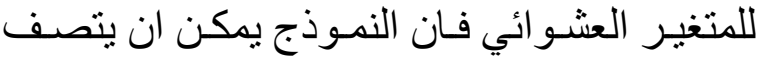

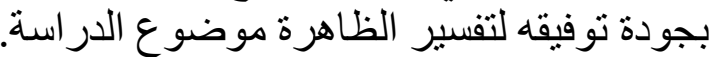
رابعا: تقديرات النموج الخاص بالصين:

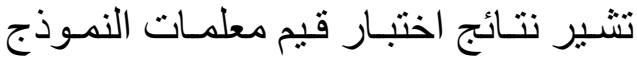
الخاص بالطلب على المصـادر البديلـة للنفط الخـام

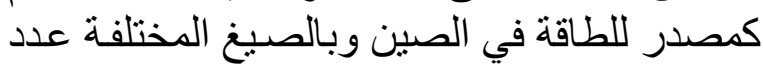
من الملاحظات لعل اهمها عدم معنوية تاثير معدل

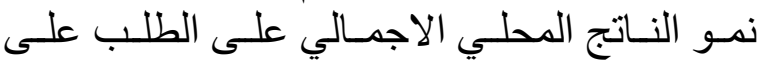

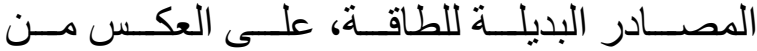

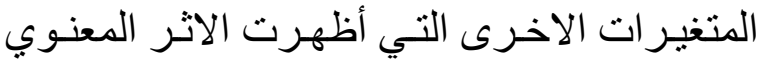

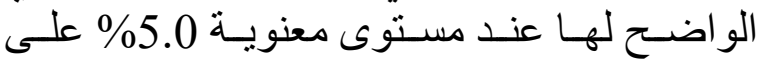

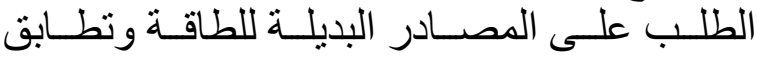
اشار اتها مع التوقعات المسبقة للنظرية الاقتصادية.

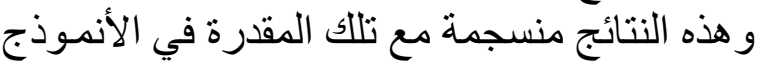

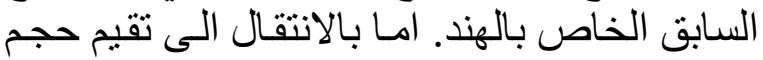

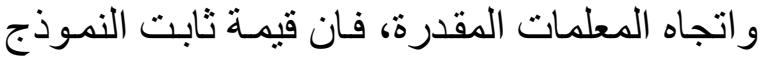
تشير الى ان الطلب على الطاقة البديلة للنفط الخـام

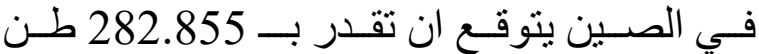

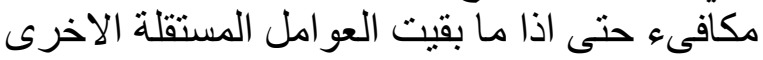

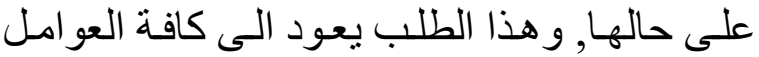

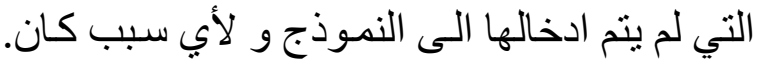

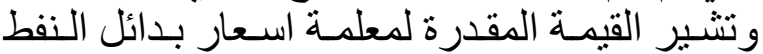

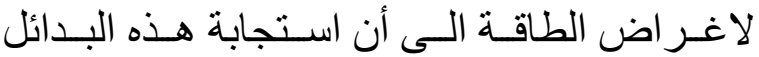

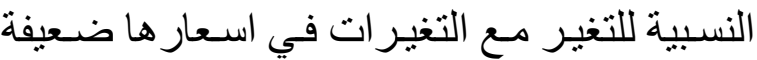

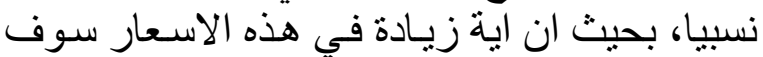

الطلب المذكور وبنسبة 35.8\% من تلك النسبة. و هذا يمكن ان يعود الى ما يلي: الئي:

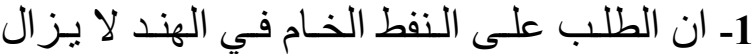

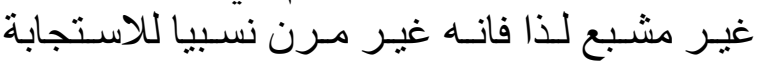
للتغير ات في اسعار ها.

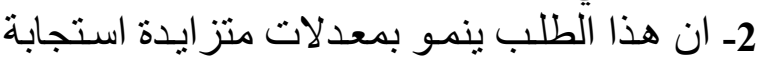

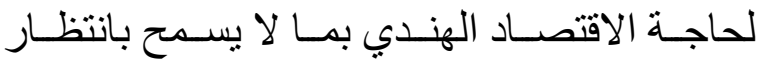
الطاقة البديلة.

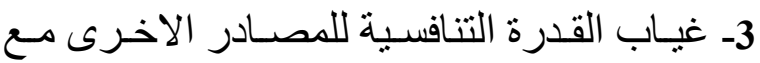

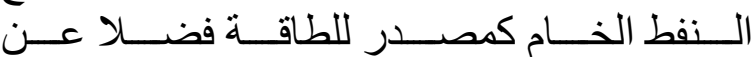
الاستخدامات البديلة له.

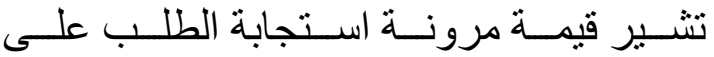

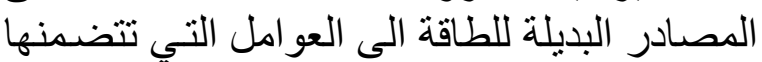

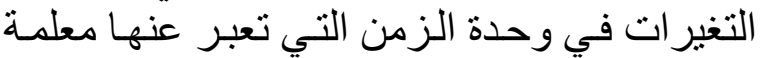

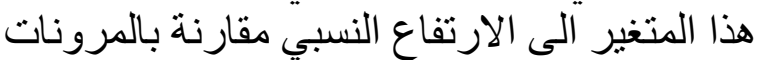

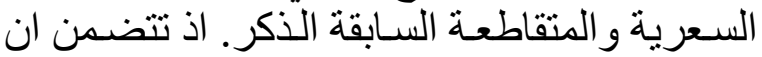

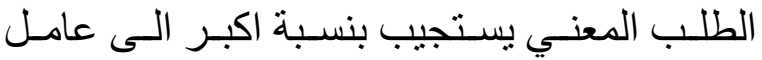

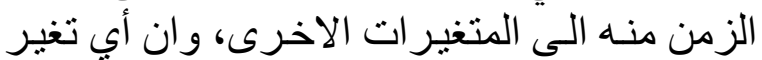

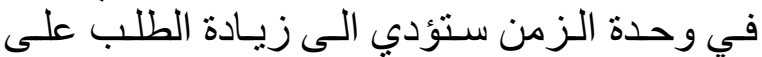
بدائل النفط الخام ولكن بنسبة اقل من ذئ ذلك التغير.

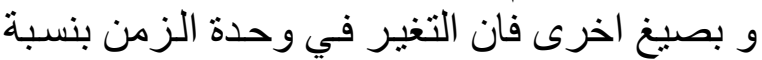

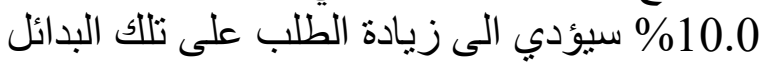

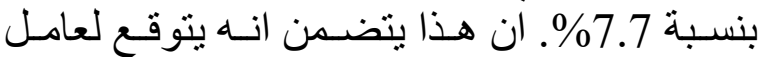

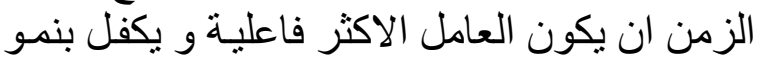

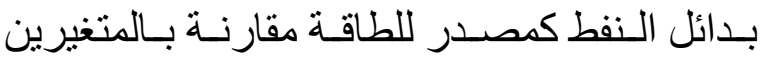

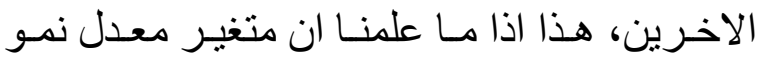

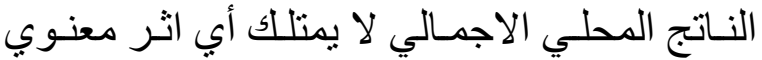

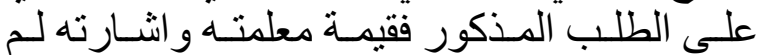
يتجاوز ا الاختبار ات الاحصائية الممثلة باختبار (t).

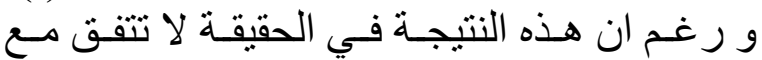

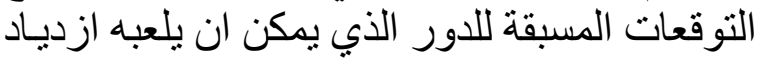

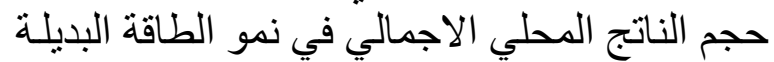

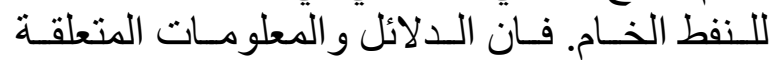

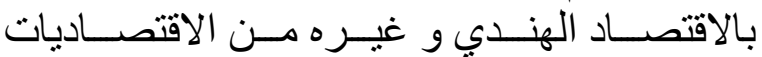

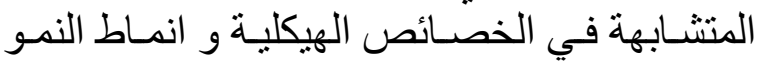

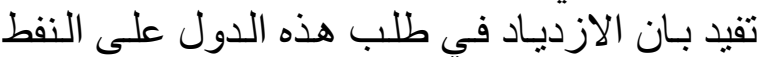

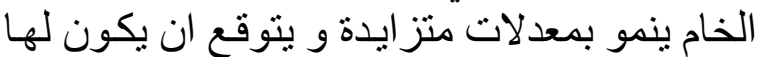
تاثثير كبير على اسعار النفط الخام و ذللك بفعل نمو التهو

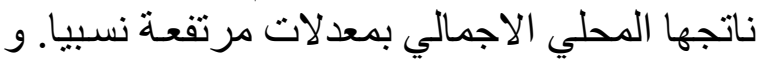

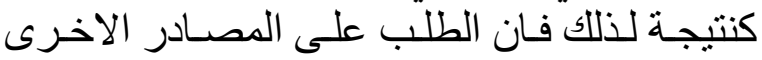
البديلة للطاقة يبقى هامشيا لانه غير قادر في الواقع الون 
الاقتصاديات النامية كالاقتصادين الصيني و الهندي

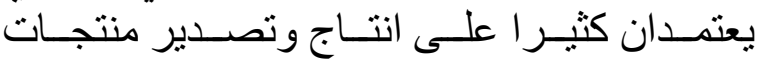

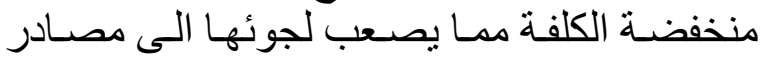
مكلفة للطاقة.

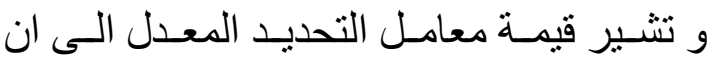

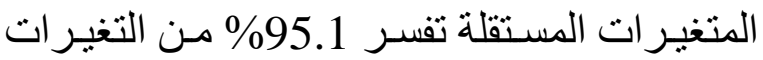

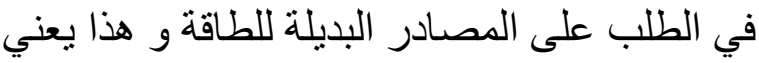

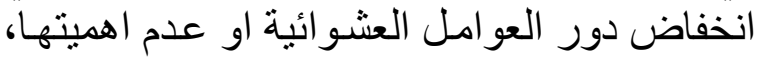

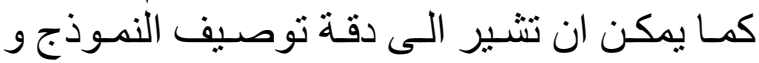

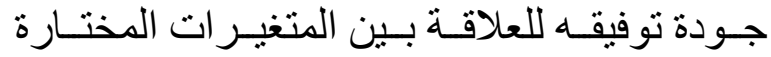

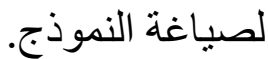

\section{خامسا: تقييم وتحليل تقديرات أنموذج بلدان}

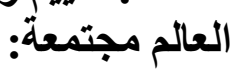

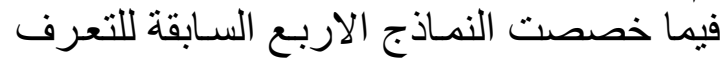

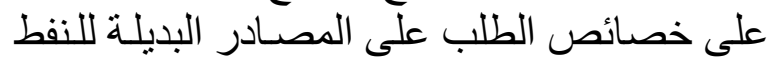

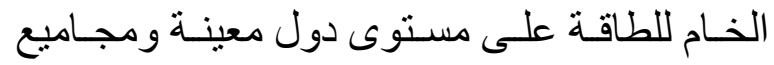

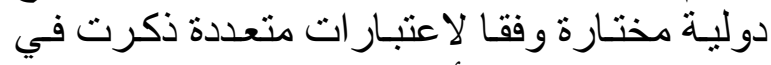

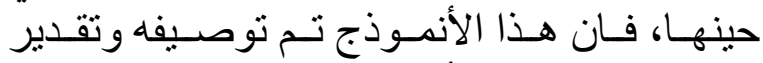

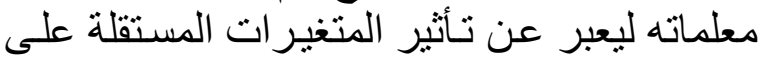

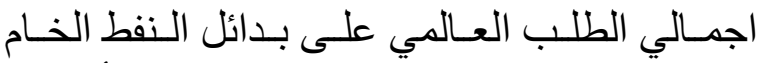

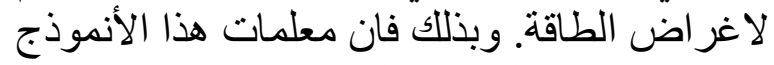

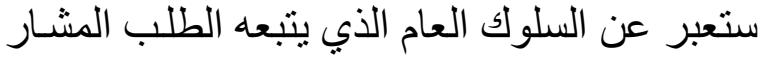

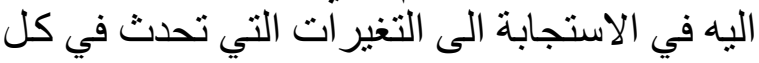

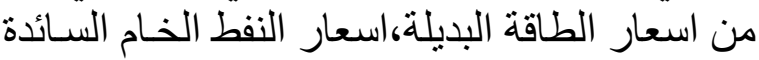

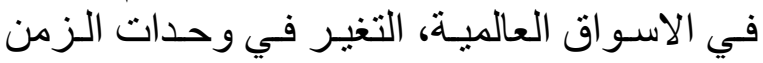

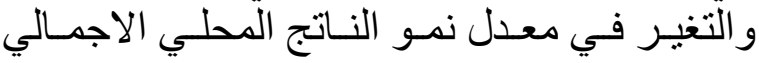

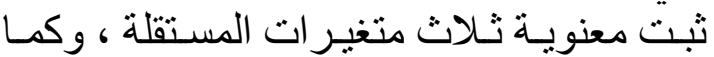
العالمي.

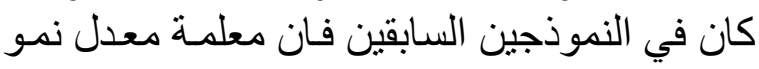

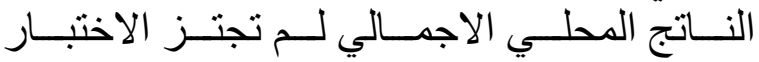

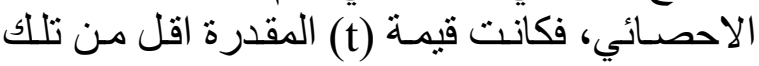

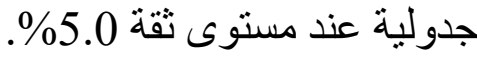

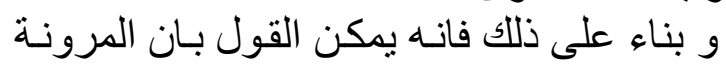

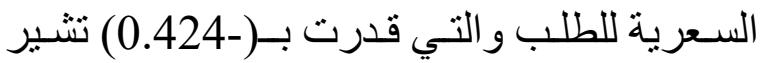

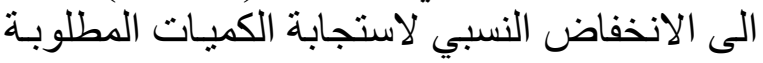

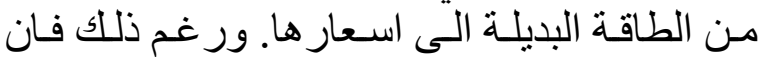

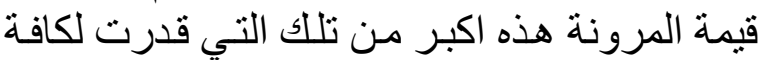

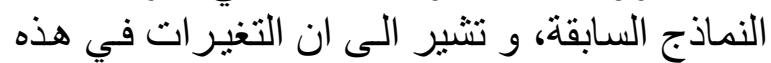

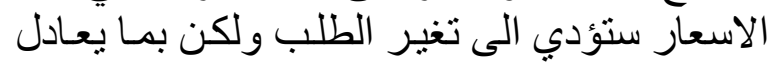

لا تساهم في ازدياد الطلب على الطاقة البديلة للنفط

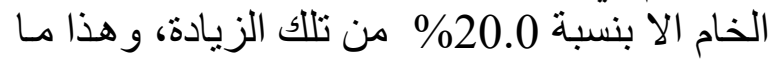

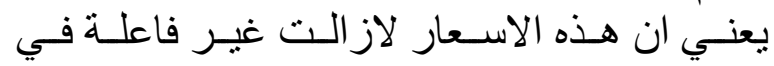

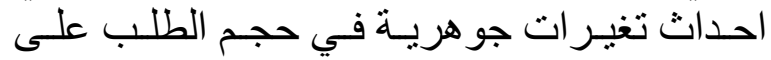

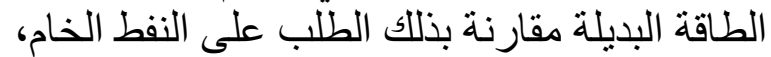

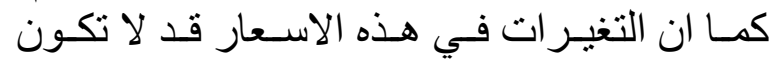

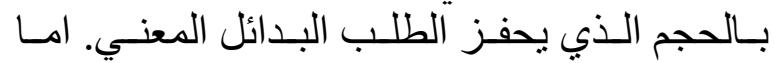
بالنسب لطبيعة التأثير المقدر لاستعار النفط الخـام

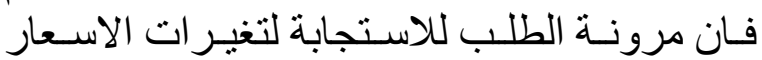

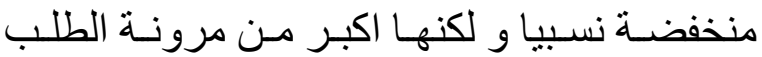

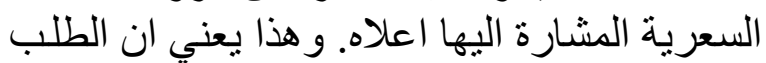

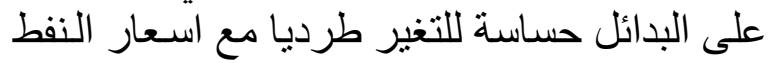

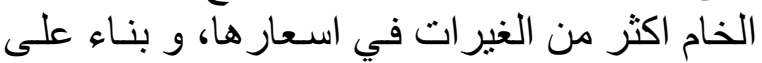

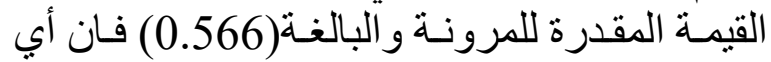
تغير في اسعار النفط الخام بنسبة 10.0\%

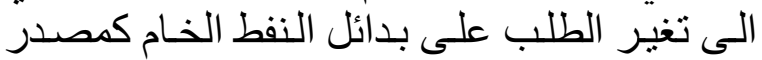

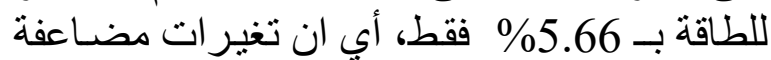

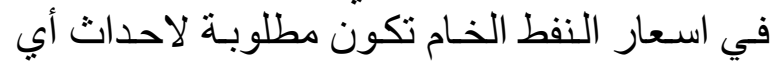
تغير في الطلب المذكور.

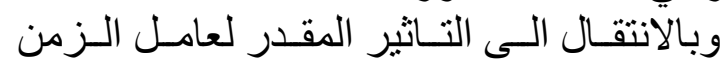

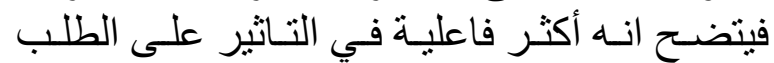

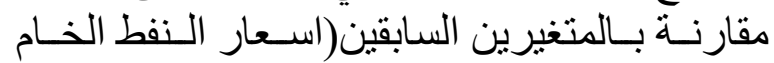

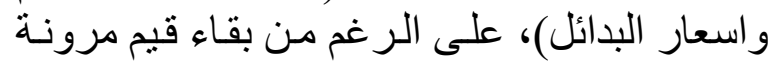

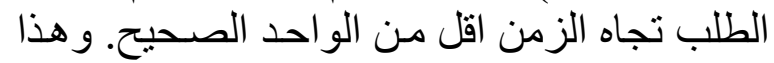

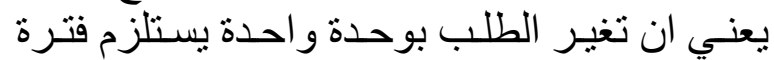

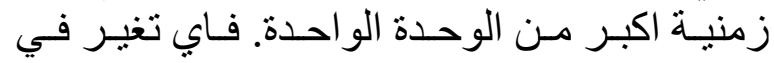

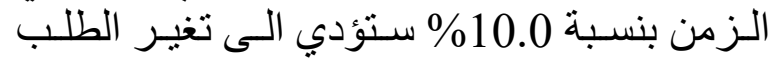

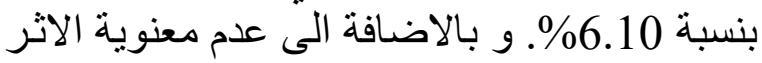

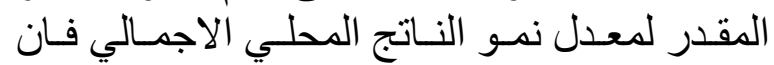

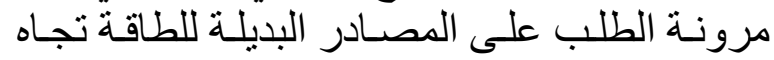

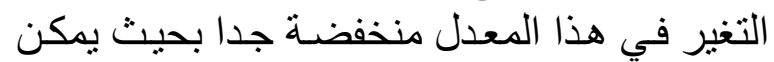

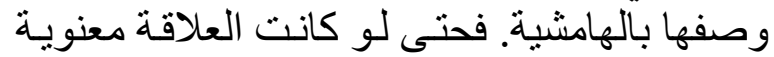

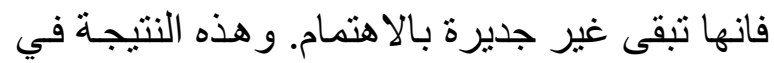

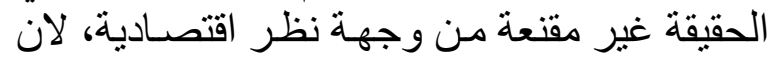

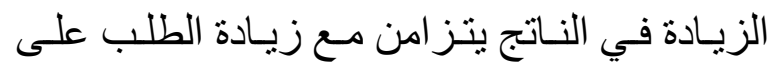

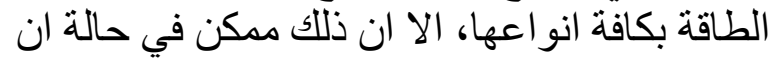

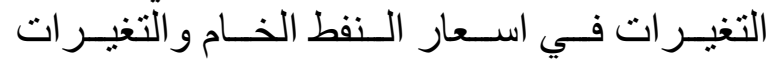

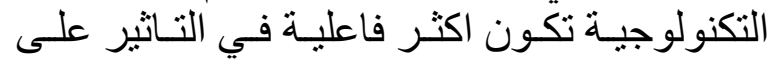

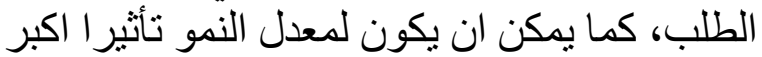

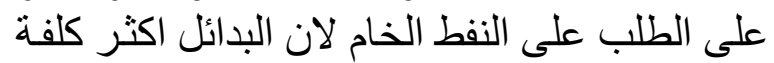

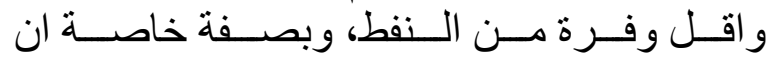


و فيما يخص متغير الزمن، فيلاحظ ان مرونـة

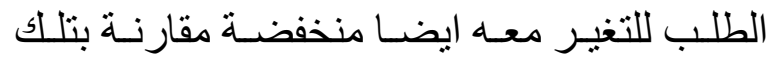

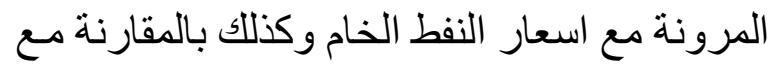

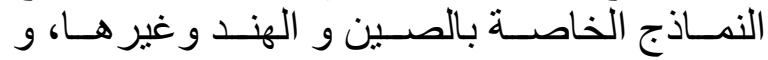

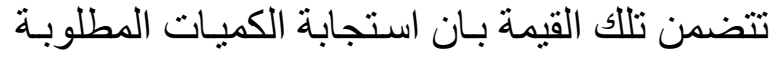

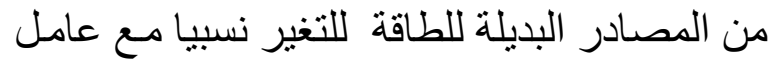

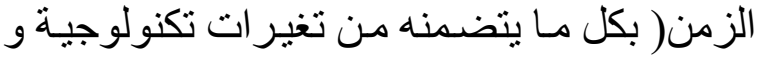

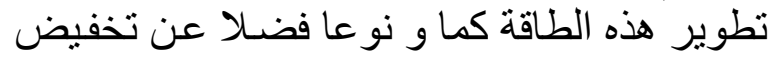

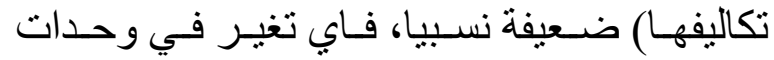

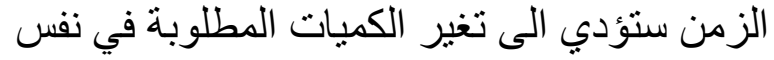

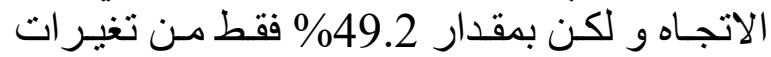

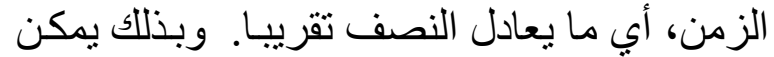

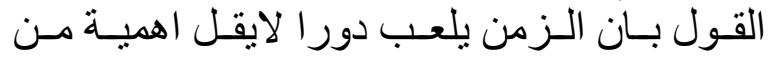
عو امل اخرى عديدة في تطوير بدائل النفط الخـام

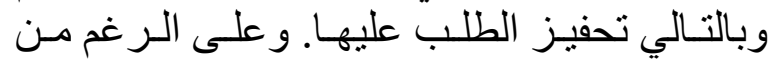

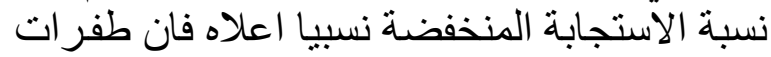

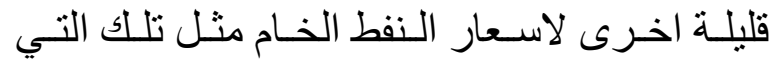

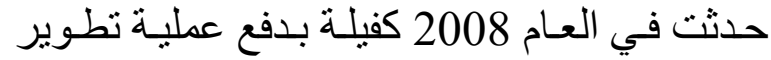

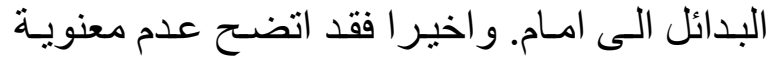

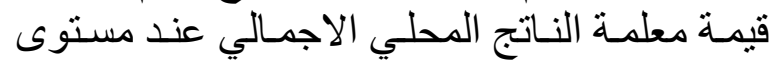

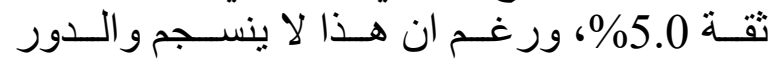
المتوقع لنمو الناتج على هذا الطلب، الا ان التف التفير

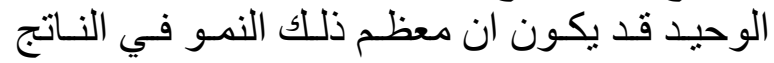

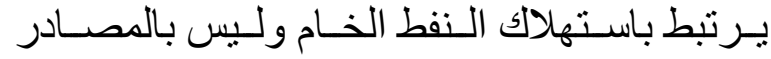

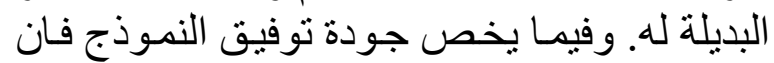

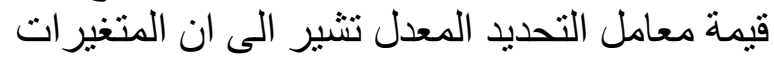

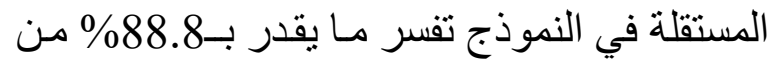

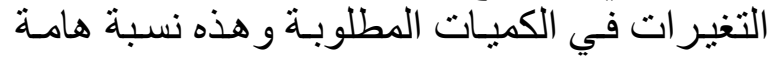

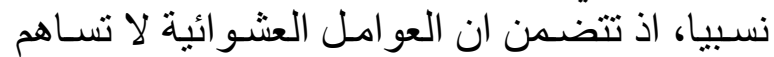
سوى بـ 1.2\% من التغير ات في المتغير المعتمد.

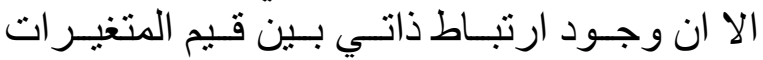

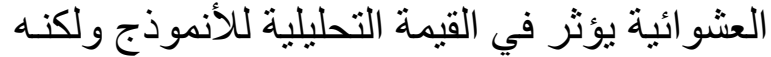
لايقلل من اهميته وذلك فئل الانسجام العلاقـات المقدرة مــع غالبيـة المعـايير الاقتصــادية و الاحصــائية و القياسية.

\section{الاستنتاجات}

بناءا على مـا توصـل إلبـه في الفصـول البحثيـة

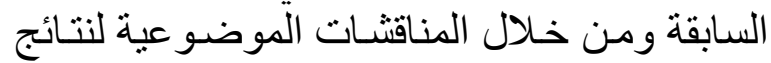
التحليـل و المؤشر ات المقدرة مـن النمـاذج القياسية
42.4\% من حجم التغير في الاسـعار. و هنـا يمكن

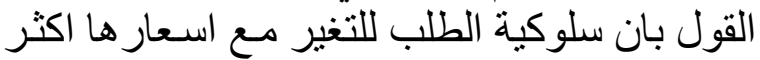

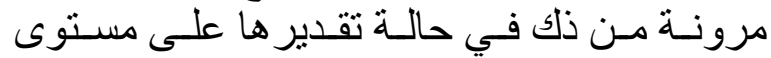

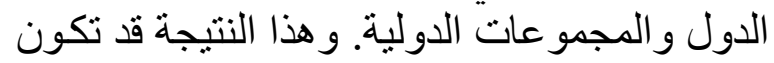

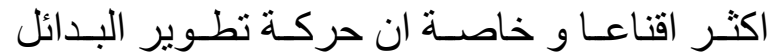

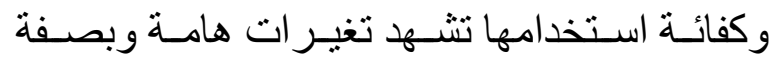

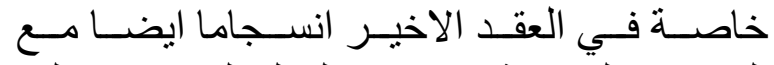

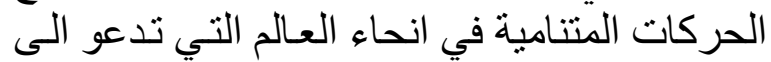

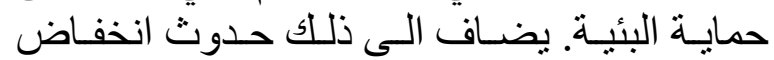

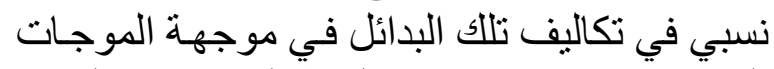

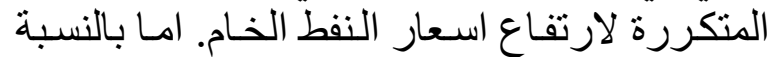

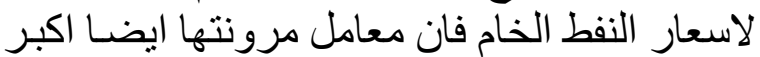

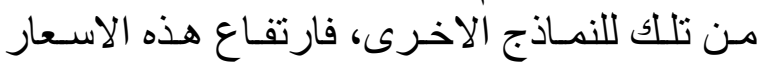

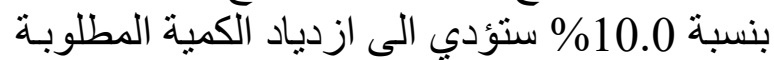

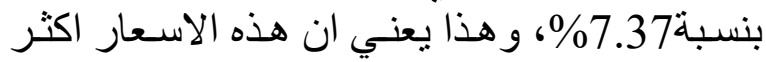
فاعلية في التاثير على الطلب. ولكون الكون قيمة المرونة

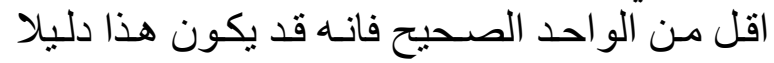

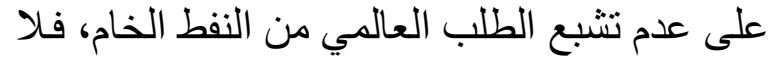

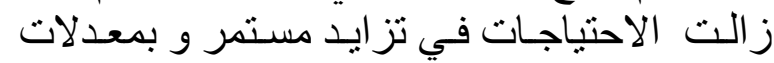

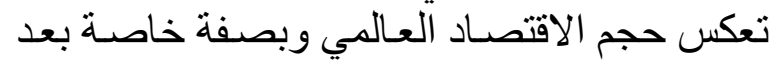
ظهور اقتصاديات تحقق معدلات نمو كبيرة نسبيا

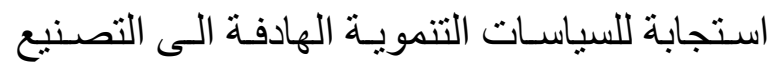

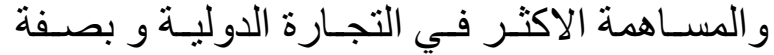

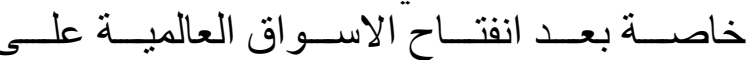

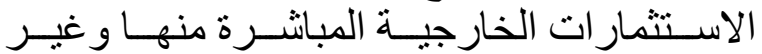
المباشرة والتي ادت الى ايجاد فرص كثير للتشغيل التشيل

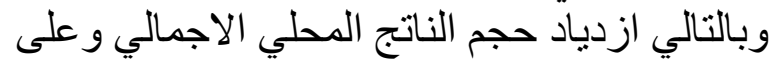

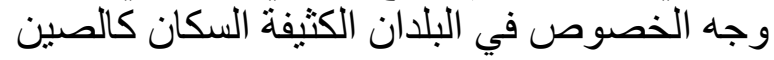

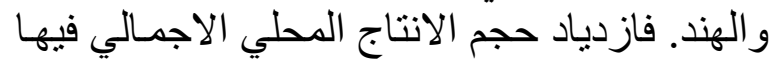

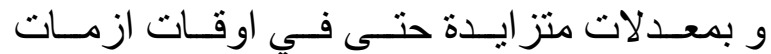

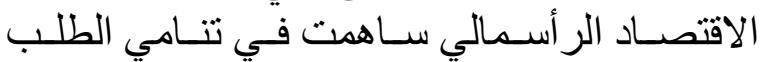

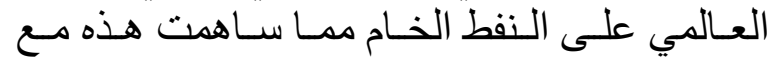

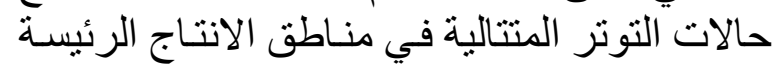
الى حدوث زيادات كبيرة ومفاجئة في اسعار النفط الخام وخاصة في السنو ات القليلة الماضية. فانه من الطبيعي ان تكون لمثل هذه الزيـادات في

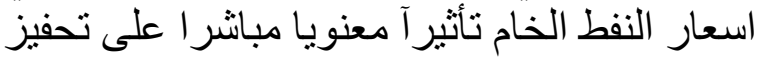

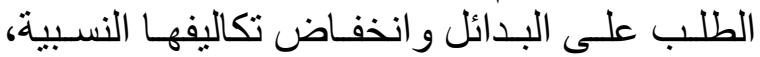

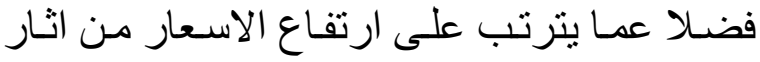
غير مباشرة على اسواق الطاقة عموما. 
عرض البدائل من جهة وارتفاع تكاليفها النسبية

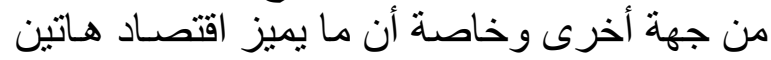

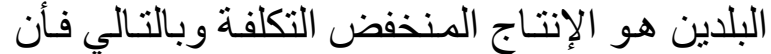

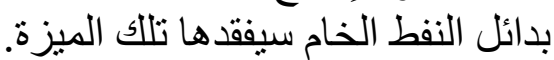
10-إن القيم المقدرة لمعلمـات المتغير ات المستقلة الفيلة

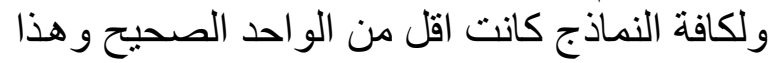

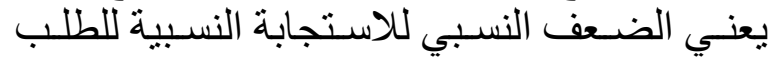

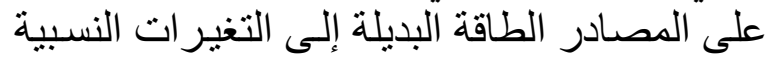

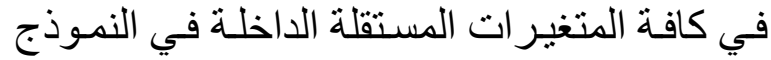

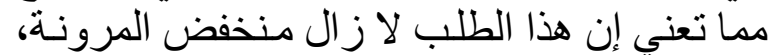

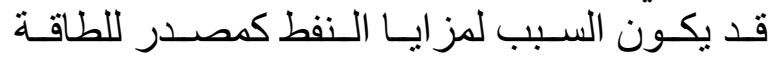
واستخدامات أخرى الأثر الأكبر على ذللك.

المقترحات

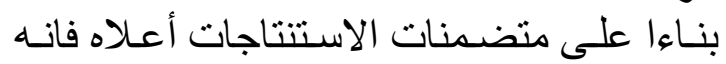

يمكن التوصية بالمقترحات المشنار إلبها أدناه:

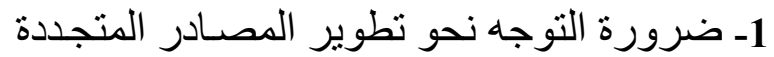

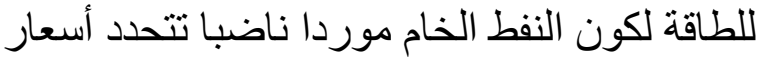

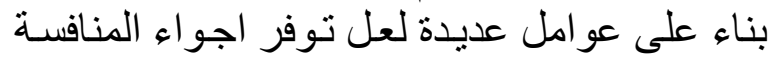
للمصادر البديلة لها اهم تللك العو امل.

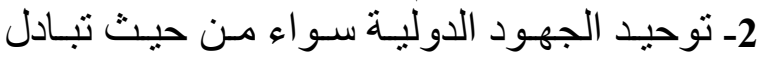

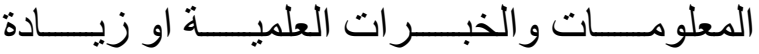
التخصيصات المالية في مجال البحث العلمي الذي الذي التي

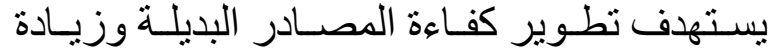
إنتاجها بتكاليف منافسة.

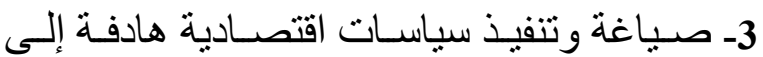

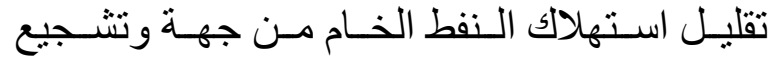

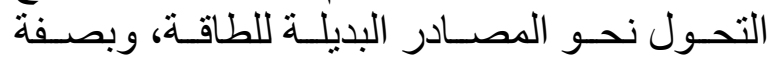
خاصة السياسات الضريبية الفعالة.

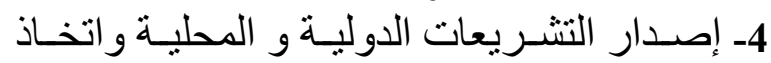

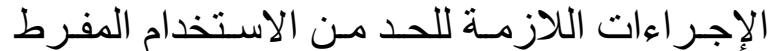

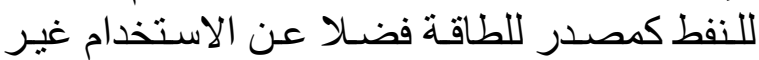
المتفق مع المعاير البيئية.

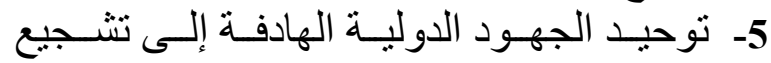
النشـاطات الاقتصـادية الصـديقة للبيئة وذلك عن الكن طريق استخدام مصادر الطاقة الصديقة للبيئة.

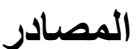

أولا: المصادر العربية: أـ الرسائل والأطاريح الجربية: الجامعية:

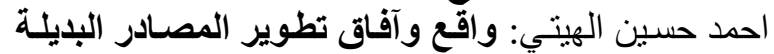

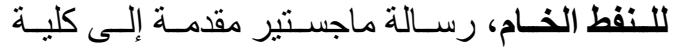

و المحتسبة من البيانـات و المعلومـات المتوفرة فانـه

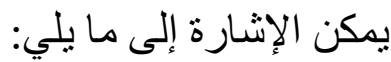
1- تبين من هيكل الطلب على الطاقة لعام 2008،

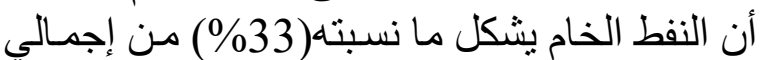

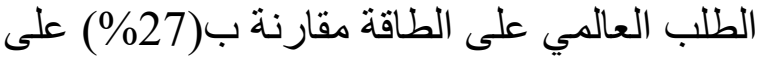

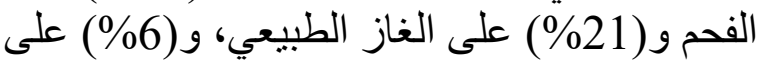

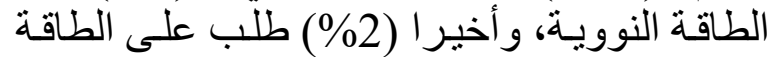

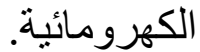
2- تبين من هيكل الطلب على الطاقة لعام2008،

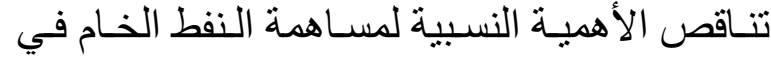
إجمالي ميز ان ميزان الطاقة العـالمي، فبينمـا كانت عام1973 شكل ما نسبته (45\%) مقابـل مـا نسبته

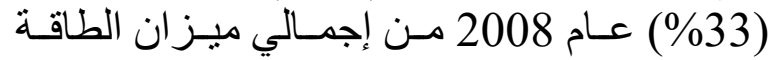

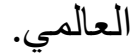

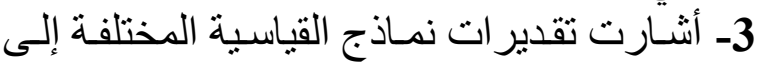

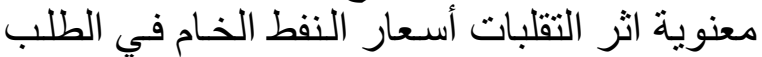

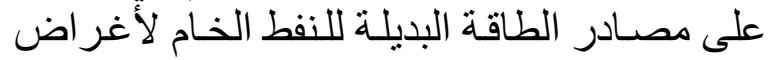

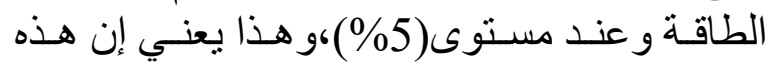

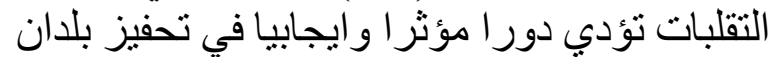

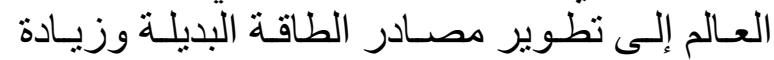
إنتاجها وبالتالي عرضها بأسعار منافسة. 4- ظهور الأثر المعنوي لأسعار الطاقة البديلة في

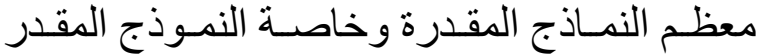

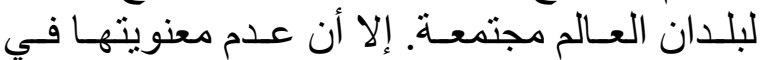

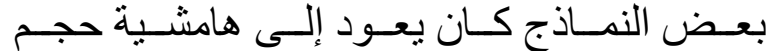

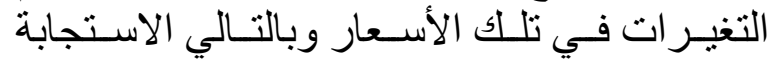

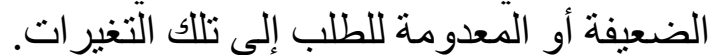
5- تبين أن لعامل الزمن( بما يتضدنه من تغير الميرات تكنولوجية وجهود علمية المتعلقة ب تطوين النير البدائل وزيادة إنتاجها وكفاءتها النسبية وقدرتها التنافسية

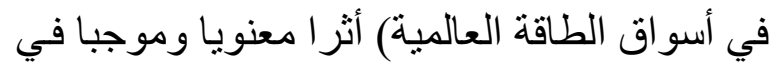

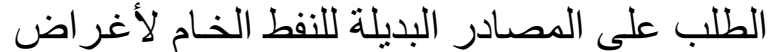
الطاقة. 6- تبين وجود اثر معنوي للتغير ات في معدل نمو

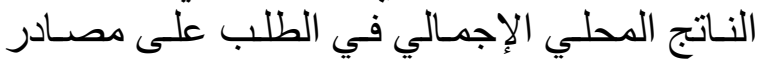

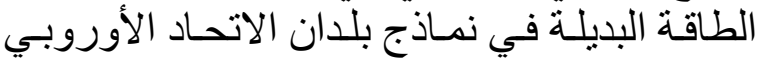

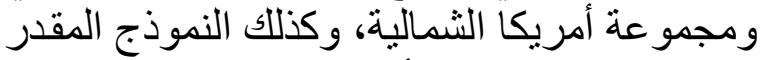

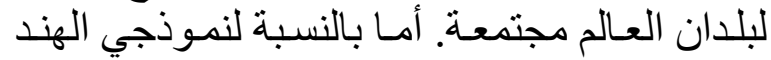

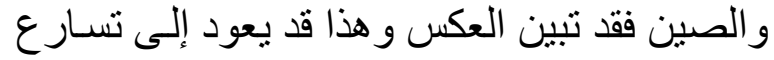

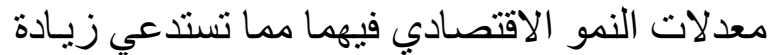
الطلب على النفط الخام و عدم إمكانية انتظار زيادة 
Harold Hotelling: The Economic of Exhaustible Resources, Journal of political Economy,VOL.3,Issue.2,April-1931.

Irene Henriques \& Perry Sadorsky: Oil prices and the stock prices of alternative energy companies, Energy Economics, VOL. 30, USA, 2008.

www.sciencedirect.com

Josef Braml: Can the United States Shed Its Oil Addiction?, The Washington Quarterly, VOL.30, NO.4, USA, autumn-2007.

Melamid, Geography of the World Petroleum Price Structure, Economic Geography, Vol. 38, No. 4, Oct- 1962.

Noureddine K.: World crude oil and natural gas: a demand and supply model, Energy Economics USA, VOL.24, NO.13, 2002.

P. F. Chester: Prospects for alternative-energy sources in Electricity generation, power engineering journal, USA, July 1989.

Robert M. Solow: The Economics of Resources or the Resources of Economics, The American Economic Review, Vol.64, No.2, May 1974.

Robert Pirog: World Oil Demand and the Effect on Oil Prices, CRS Report for Congress, August 18, 2004. www.fas.org/sgp/crs/misc/RL32530.pdf

Rumi Masih, Sanjay Peters\& Lurion De Mello: Oil Price Volatility and Stock Price Fluctuations in an Emerging Market: Evidence from South

Korea,

April,2010..http://www.iese.edu

S. Fred Singer: Oil Policy in a changing market, Annual review of energy, VOL 12, USA 1987.

S. Hayden Lesbirel: The Political Economy of Substitution Policy: Japan's Response to Lower Oil Prices, Pacific Affairs, University of British Columbia, Vol.61, No.2, Summer 1988.

Stephen A. H. \& Russell R. C.: Factors That Will Influence Oil and Gas Supply and Demand in the 21st Century, VOL.33, April 2008.

C- Books: www.mrs.org

A Scoot Fetzer company:The World Book Encyclopedia,vol.15, Chicago, 2003.

Robert H. Frank: Microeconomics and Behavior, $7^{\text {th }}$ Edition, McGraw-hill, USA, 2008.

D- Internet Sites:

www.ivsl.org

www.eia.doe.gov

www.api.org.

www.bp.com

www.worldbank.org
الإدارة والاقتصــاد جامعـة بغـداد (غير منشـورة)،

.1979

$$
\begin{aligned}
& \text { بـ البحوث و الاوريات: } \\
& \text { د. جعفر منصور سـد: تدهور الدولار وأثناره على الدول }
\end{aligned}
$$

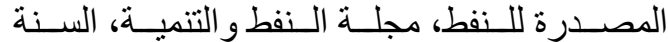

$$
\begin{aligned}
& \text { الر ابعة، العدد 3، بغداد، كانون الأول } 1978 .
\end{aligned}
$$

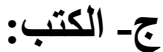

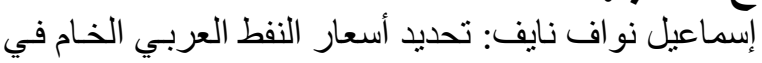

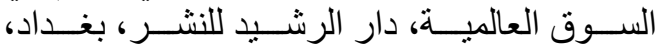

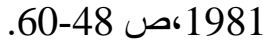

$$
\begin{aligned}
& \text { توبي شيللي: النفط ( السياسـة،وروالفقر،و الكوكب)، ترجمتهـا } \\
& \text { للعربية: دينا عبدالاله الملاح، العبيكان ،السعودية، العية، } \\
& \text { 2010 } \\
& \text { د. سمير التنبر: التطور ات النفطية في الوطن العربي و } \\
& \text { العالم،الجزء الاول، دار المنهل اللبناني، بيروتي، النيرئ } \\
& 2007 \\
& \text { فؤاد قاسـم الأمير : (الطاقـة: التحدي الأكبر هذا القرن)، }
\end{aligned}
$$

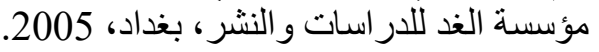

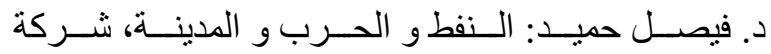

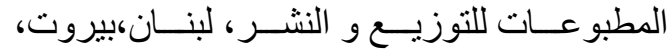

$$
\begin{aligned}
& \text {.2007، } \\
& \text { ثانيا: المصادر الانكليزية }
\end{aligned}
$$

\section{A-Official Report \& Statistics:}

BP Statistical Review of World Energy,for years: 1981,1995,2004,2009,

(I.E.A.) International Energy Agency: Annual Report, for years: 2006, 2009,2010

(I.E.A.) International Monetary Fund: World Economic Outlook, 2010

\section{B-Articles:}

Arón G. \& Sherzod N.: Oil price fluctuations and its effect on GDP growth, A case study of USA and Sweden, 2009, http://su.divaportal.org/

Anthony Schmitz: Effect of Oil Prices on Returns to Alternative Energy Investments, Georgia Institute of Technology, USA, December, 2009.

C.-Y. Cynthia Lin: Insights from a Simple Hotelling Model of the World Oil Market, Natural Resources Research, California, USA, Vol.18, No.1, March-2009.

Gopal Pottabathni: Oil Price Fluctuations - Its Effects of Alternative Energy, Resources,2009.http://ezinearticles.com 


\title{
THE IMPACT OF OIL PRICES FLUCTUATIONS ON DEMAND FOR ALTERNATIVE ENERGY RESOURCES
}

\author{
Khalil G. Hassan and KHabBat ABdulKareem SAID
}

Dept. of Economic, College of Admonition and Economic, University Of Duhok, Kurdistan Region-Iraq

\begin{abstract}
Crude oil is one of the most important and depleted resources used as an energy source for decades. While high oil prices have slowed global economic activity, they are a major cause of the shift towards alternative energy sources.

This study is an attempt to answer the question of whether fluctuations in crude oil prices will shift to alternative sources and thus reduce the relative importance of crude oil in the global energy balance. In favor of alternative energy sources, alternative energy demand models have been estimated at several levels, including individual countries such as China and India, a group of countries such as the European Union, the North American group and, finally, the overall level of the world. To achieve the objectives of the research and test its hypothesis, the parameters to be estimated according to the methodology of econometrics were analyzed.

Perhaps the most important conclusion is the significant impact of fluctuations in crude oil prices on the demand for alternative sources of crude oil for energy purposes.
\end{abstract}

